\title{
Zooplankton diel vertical migration in the Corsica Channel (north-western Mediterranean Sea) detected by a moored acoustic Doppler current profiler
}

\author{
Davide Guerra $^{1}$, Katrin Schroeder ${ }^{1}$, Mireno Borghini ${ }^{1}$, Elisa Camatti ${ }^{1}$, Marco Pansera $^{1}$, Anna Schroeder $^{1,2}$, \\ Stefania Sparnocchia ${ }^{1}$, and Jacopo Chiggiato ${ }^{1}$ \\ ${ }^{1}$ Consiglio Nazionale delle Ricerche, Istituto di Scienze Marine (CNR-ISMAR), 30122 Venice, \\ 19036 La Spezia, 34149 Trieste, Italy \\ ${ }^{2}$ University of Trieste, Faculty of Environmental Life Science, 34127 Trieste, Italy
}

Correspondence: Katrin Schroeder (katrin.schroeder@ismar.cnr.it)

Received: 6 August 2018 - Discussion started: 7 September 2018

Revised: 17 April 2019 - Accepted: 6 May 2019 - Published: 29 May 2019

\begin{abstract}
Diel vertical migration (DVM) is a survival strategy adopted by zooplankton that we investigated in the Corsica Channel using acoustic Doppler current profiler (ADCP) data from April 2014 to November 2016. The principal aim of the study is to characterize migration patterns and biomass temporal evolution of zooplankton along the water column. The ADCP measured vertical velocity and echo intensity in the water column range between about 70 and $390 \mathrm{~m}$ (the bottom depth is $443 \mathrm{~m}$ ). During the investigated period, zooplanktonic biomass had a well-defined daily and seasonal cycle, with peaks occurring in late winter to spring (2015 and 2016) when the stratification of the water column is weaker. Zooplanktonic biomass temporal distribution in the whole water column is well correlated with biomass of primary producers, estimated with satellite data. Zooplanktonic blooming and non-blooming periods have been identified and studied separately. During the non-blooming period zooplanktonic biomass was most abundant in the upper and the deep layers, while during the blooming period the upper-layer maximum in zooplanktonic biomass disappeared and the deep layer with high zooplanktonic biomass became thicker. These two layers are likely to correspond to two different zooplanktonic communities. The evolution of zooplanktonic biomass is well correlated with chlorophyll, with phytoplankton biomass peaks preceding the upper-layer secondary production by a lag of about 3.5 weeks. Nocturnal DVM appears to be the main pattern during both periods, but
\end{abstract}

reverse and twilight migration are also detected. Nocturnal DVM was more evident at mid-water than in the deep and the upper layers. DVM occurred with different intensities during blooming and non-blooming periods. One of the main outcomes is that the principal drivers for DVM are light intensity and stratification, but other factors, like the moon cycle and primary production, are also taken in consideration.

\section{Introduction}

Diel vertical migration (DVM) is one of the most important survival strategies adopted by zooplankton. During migration these marine organisms can cover vertical distances of a few hundred metres. During nocturnal migration at dawn zooplankton descends and remains at depth, where the probability of being predated by a visually hunting predator is lower; at dusk zooplankton rises to the euphotic layer and stays there during night to feed on phytoplankton (Ringelberg, 2010; Zaret and Suffern, 1976). This is only one of the three most common migration patterns. Indeed, twilight migration (ascent at dusk and sunrise, descent at midnight and immediately after sunrise) and reverse migration (ascent at sunrise, descent at sunset) have also been described in previous studies (Haney, 1988, and references therein). The typical descent of twilight migration that occurs during night is called midnight or nocturnal sinking and is a downward 
movement accomplished after the sunset ascent and before the sunrise descent, which some zooplanktonic organisms do to leave the surface feeding layer and return to depth (Pearre, 2003, and references therein). Indeed, many authors agree on the presence of a continuum of migrating behaviours between the two opposed patterns of nocturnal and reversed migration (Haney, 1988). Essentially, in nocturnal DVM, the benefit of a reduced probability of predation is suggested to outweigh the cost of being spatially separated from the nearsurface food, with a resulting reduced potential for daytime feeding (Hays, 2003). The less common twilight and reverse migration patterns have advantages as well, one of which could be to avoid other nocturnal migrators, such as nonvisually hunting invertebrate predators or simply competitors (Heywood, 1996; Ringelberg, 2010).

DVM is widespread and found within practically all taxonomic zooplankton groups, so it is generally assumed that there must be a common underlying reason for such behaviour (Pearre, 2003). Pioneering studies (Clarke, 1934; Eyden, 1923) hypothesized that migrators ascend into food-rich layers when hungry and descend after feeding, thus directly linking DVM to feeding. Likewise, Hardy (1953) and Stuart and Verheye (1991) suggested that carnivorous migrators, such as chaetognaths, might be simply following their herbivorous prey. However, in some cases, diel migration appears to have no link to feeding, e.g. when benthically feeding animals rise at night (as reported e.g. by Neverman and Wurtsbaugh, 1994). On the other hand, theories of migration based only on light or temperature effects as driving factors might not fully explain this complex biological phenomenon and ignore individual behaviours and responses to the environment (Gibbons, 1993). Laboratory studies show that organisms kept constantly in the dark, with similar in situ conditions, continue to maintain a damped DVM rhythm, with an evening ascent and a clear downward movement in the morning (Häfker et al., 2017). This suggests the importance of an endogenous circadian biochemical internal clock and might explain the midnight sinking, the sunrise ascent (twilight migration) and DVM within the aphotic layer (van Haren and Compton, 2013). In fact, DVM is conditioned by a larger number of endogenous and exogenous factors (Ringelberg, 2010). Among the endogenous factors are sex, developmental stage, age, genotype, size and internal rhythms (Richards et al., 1996), while exogenous factors include light, food availability, gravity, thermohaline characteristics (temperature, salinity, stratification), oxygen and hydrostatic pressure.

Studying the diel vertical distributions of zooplanktonic biomass is essential to achieve a better understanding of the functioning of pelagic ecosystems and the biological pump. By feeding near the surface at night and then fasting at depth during the day, where it continues to defecate, respire and excrete, migrating zooplankton removes carbon and nitrogen from the surface layers and releases them at depth (Hays et al., 1997; Longhurst and Glen Harrison, 1989; Schnetzer and Steinberg, 2002). Vertical migrators (including both zoo- plankton and phytoplankton) play a relevant role in the vertical fluxes of matter and energy in the marine environment. The net direction of this flux is downward, although migrators are able to return significant amounts of matter and energy upward, contributing to the effective recycling of nutrients within the euphotic zone (Pearre, 2003), thus supporting regenerated primary production.

Traditionally, DVM surveys are very time and labour intensive. Emerging technologies, such as acoustic techniques, can reduce this investment, greatly increasing the ability to decrypt the drivers, benefits for migrating organisms and total extent of vertical migrations. The acoustic Doppler current profiler (ADCP) is a widespread instrument used to measure water current profiles. Since the pioneering work of Flagg and Smith (1989) ADCPs have been used to investigate zooplanktonic DVM and zooplanktonic biomass from measurements of vertical velocity and echo intensity (a measure of acoustic backscattered energy). The operating principle of ADCP is based on sound backscattering by particles (such as sediments, organisms or bubbles) suspended in the water. The instrument emits acoustic impulses with known frequency and receives the echoes with a shifted frequency. The frequency shift is directly proportional to the velocity of the moving particles (Doppler effect) and is used to infer the velocity and direction of passive particles suspended along the water column (Teledyne RD Instruments, 2011). The basic assumption is that the particles are passively carried by water masses and that they move together at the same speed. It is not possible to determine exactly how much of the sound-reflected signal is due to zooplankton, since the acoustic waves are reflected by all objects with a size of about $1 / 4$ of the wavelength of the acoustic impulses (Thomson and Emery, 2014). If we consider the speed of sound in seawater around $1475 \mathrm{~m} \mathrm{~s}^{-1}$ and the ADCP working frequency of $76.8 \mathrm{kHz}$, the wavelength is about $1.9 \mathrm{~cm}$, so objects greater than $0.48 \mathrm{~cm}$ reflect sound, while objects smaller than this scatter the sound. However, since swarms of zooplankton tend to aggregate at specific depths, smaller organisms can also be easily detected because the acoustic backscatter strength is proportional to the density distribution of organisms (Iida et al., 1996).

In zooplankton DVM studies, two important assumptions are usually made: vertical velocity detected by an ADCP is principally due to zooplankton motion under general oceanic conditions with negligible upwelling and downwelling phenomena (Heywood, 1996), as is the case in the Corsica Channel (e.g. Bakun and Agostini, 2001), and sound backscatter is due, in most cases, to zooplanktonic biomass (Wormuth et al., 2000). Sound backscattering is influenced by organism shape, orientation (Chu et al., 1992) and consistency; e.g. organisms made up mostly of protoplasm do not backscatter the acoustic signal proportionally to their size (Flagg and Smith, 1989) but can indeed also be due to phytoplanktonic organisms or turbulent events. Thus, in general, information 


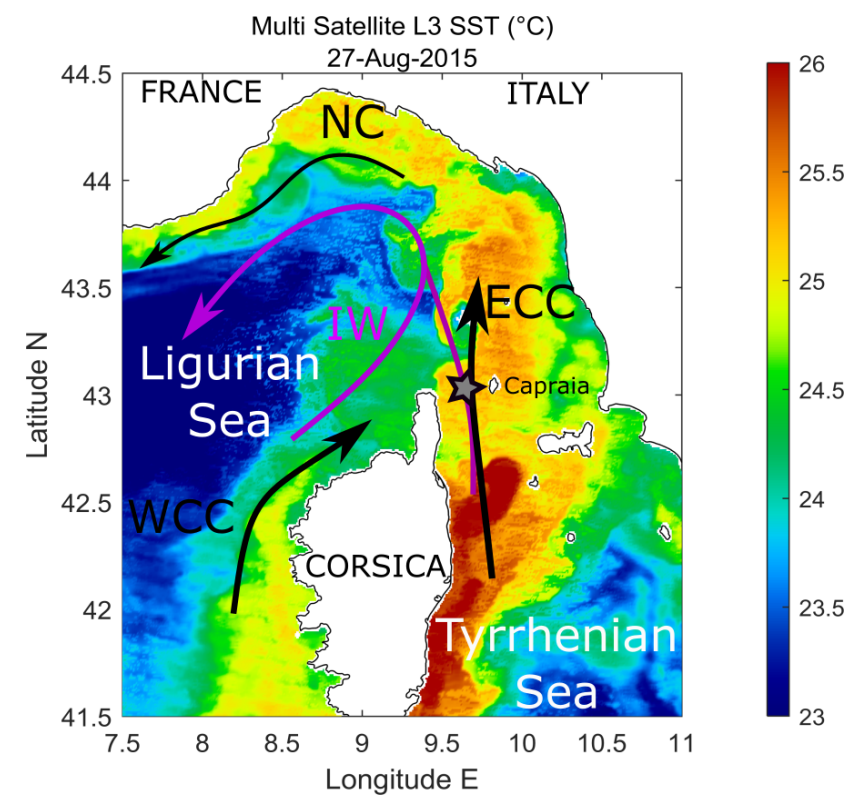

Figure 1. Map of the area. Main current features (ECC: Eastern Corsica Current; WCC: Western Corsica Current; NC: Northern Current; IW: Intermediate Water pathway) and the position of the moored ADCP (star) are indicated. In the background (colour coded), the sea surface temperature (SST) field from a sample day (27 August $2015,{ }^{\circ} \mathrm{C}$ ) is provided to highlight the mesoscale and frontal systems (source CMEMS).

on zooplanktonic biomass and vertical motion inferred from ADCP data is more qualitative than quantitative.

In this study an upward-looking ADCP, moored at about $400 \mathrm{~m}$ of depth within the $443 \mathrm{~m}$ deep Corsica Channel (western Mediterranean Sea) between Corsica and Capraia islands (Fig. 1), was used to investigate the DVM of zooplankton and its biomass variations along the water column from April 2014 to November 2016. The ADCP is part of a long-term fixed deployment (CIESM Hydrochanges Programme; Schroeder et al., 2013) and is used to measure water properties and currents, so the setting of the instrument was not originally intended for the application presented here. However, although the temporal and spatial resolutions are not in the optimal ranges, this method still provides valuable insight on zooplankton DVM in the north-western Mediterranean Sea. The information derived by the ADCP is complemented by a morphological community analysis of in situ samples obtained with two net casts in the same area in August 2015. Conductivity-temperature-depth (CTD) casts performed from a ship during maintenance operations on the mooring and from a moored profiling system provided data to characterize the study site.

To better interpret the ADCP data it is essential to know which organisms are common in the zooplanktonic community of the Tyrrhenian Sea and the Ligurian Sea (Andersen et al., 1998; Pinca and Dallot, 1995; Sardou et al.,
1996; Warren et al., 2004; McGehee et al., 2004). According to previous studies (e.g. Siokou-Frangou et al., 2010), in the Mediterranean Sea copepods are the most important epipelagic mesozooplanktonic group in terms of abundance and biomass. Indeed, they represent $70 \%$ of the total zooplanktonic biomass during spring in the Ligurian Sea (Pinca and Dallot, 1955), mainly represented by e.g. Clausocalanus spp., Oithona spp. and Oncaea spp. According to Warren et al. (2014), the most abundant macrozooplankton groups in the Ligurian Sea during spring are euphausiids, such as northern krill (Meganyctiphanes norvegica), siphonophores (e.g. Chelophyes appendiculata) and salps (e.g. Salpa fusiformis and Thalia democratica). In their review on macrozooplankton and micronekton in the northwestern Mediterranean Sea, Andersen et al. (1998) and Sardou et al. (1996) also mentioned hydromedusae (e.g. Solmissus albescens), pteropods (e.g. Cavolinia inflexa), mysids (e.g. Eucopia unguiculata), Peneideae and two species of the micronektonic fish genus Cyclothone. These authors also described the vertical migratory behaviour of north-western Mediterranean species, finding an intraspecific variability in some of them that shows a bimodal distribution of their population at two different depths with consequently different migratory behaviour originating from differences in size and season.

ADCPs have been used in previous studies to investigate DVM in the Mediterranean Sea, in particular in the Ligurian Sea (Tarling et al., 2001; Bozzano et al., 2014), Ibiza Channel (Pinot and Jansá, 2001), Cretan Sea (Potiris et al., 2018), Alboran Sea (van Haren, 2014) and Adriatic Sea (Ursella et al., 2018). Bozzano et al. (2014) used acoustic backscatter data from a moored ADCP to investigate zooplankton dynamics in the upper thermocline in the Ligurian Sea. In the same area, Tarling et al. (2001) combined data collected by a vessel-mounted ADCP and net samples and found that in September the dominant groups in the first $500 \mathrm{~m}$ were euphausiids and pteropods during night, allowing for inferences on the vertical migration velocities of these swarms as well. Pinot and Jansá (2001) studied DVM in the Ibiza Channel, where they described light irradiance as the primary factor that controls DVM on a daily and seasonal basis. Potiris et al. (2018) studied the role of DVM for the functioning of the biological pump in the Cretan Sea using a moored ADCP, CTD casts, net samples and other auxiliary information on environmental conditions, finding four different patterns of nocturnal DVM (divided by depth ranges). Ursella et al. (2018) studied how a backscatter signal in the southern Adriatic Sea is linked with different environmental conditions and the presence of different zooplanktonic groups. Other studies that successfully used this technique were conducted in other parts of the world oceans, e.g. in the North Atlantic (Heywood, 1996; Jiang et al., 2007; van Haren, 2007; van Haren and Compton, 2013) and in the South Pacific (Valle-Levinson et al., 2014). Pinot et Jansà (2001), Van Haren and Compton (2013), and Potiris et al. (2018) investi- 
gated the link between the monthly lunar cycle and the DVM of deep planktonic organisms and pointed out the importance of the biochemical internal clock, while Valle-Levinson et al. (2014) found that twilight migration was predominant within Chilean fjords and was strongly influenced by the depth of the pycnocline. Most of these studies denote that acoustic data are more qualitative than quantitative because attempts to calibrate sound backscatter and zooplanktonic biomass from net samples are complex and not yet satisfactory (Flagg and Smith, 1989; Pinot and Jansá, 2001; Brierley et al., 1998).

Vertical velocity data show when zooplankton moves and in which direction, while data for acoustic backscattered energy allow us to determine the relative abundances of zooplankton present at a certain depth range and a certain time. In this study how both parameters change at different temporal scales, from daily to seasonal, and at different depth ranges is investigated. Additional data (CTD casts, net samples, satellite data, sunrise-sunset hours, moon phases) are used to identify the possible drivers of zooplankton migration in the Corsica Channel, the zooplanktonic groups that can be found in the area, what kind of migration they perform, and how their biomass varies along the water column and in time.

The paper is organized as follows. First, the study area is described based on previous knowledge and on a literature review; then, in Sect. 3, the ADCP settings and quality control procedure are described, along with the explanation on how to compute the mean volume backscatter strength from the ADCP data. Data collected by means of CTD casts, moored profiling systems, net samples, and additional systems and methods are described in the rest of Sect. 3. The presentation of the results and their discussion (Sect. 4) starts with the characterization of the water column in the Corsica Channel (thermohaline properties, stratification, oxygenation, depth of the chlorophyll maximum) and the description of the acoustic backscatter and vertical velocities on the daily and the seasonal scale. The zooplankton community composition in summer 2015 is described afterwards and put in relation to the acoustic observations of the same period. The section concludes with a lagged correlation analysis of the backscatter data and a time series of primary production in the area to look for the timing of primary production blooms vs. secondary production blooms. Finally, the conclusions are drawn at the end of the paper.

\section{Study area}

The Corsica Channel separates Corsica and Italy and is the only (narrow) connection between the Tyrrhenian Sea and the Ligurian Sea. Two water masses flow through this channel: Atlantic Water (AW) in the upper layer and Intermediate Water (IW) between 150 and $200 \mathrm{~m}$ and the bottom (maximum depth of about $450 \mathrm{~m}$ ). IW is the saltiest water mass of the whole Mediterranean Sea and originates in the eastern Mediterranean Sea; AW comes from the Atlantic Ocean, crossing the Strait of Gibraltar and flowing into the Mediterranean Sea. While moving eastward above IW, AW is continuously modified by interaction with the atmosphere and the underlying water masses, becoming gradually saltier and denser (Millot and Taupier-Letage, 2005). Both water masses enter the Tyrrhenian Sea from the south and then follow a cyclonic circulation along the Italian peninsula. When reaching the northernmost Tyrrhenian, parts of AW and IW cross the Corsica Channel (as the Eastern Corsica Current, ECC), where the mooring is located (Fig. 1), reaching the Ligurian Sea. IW flows through the channel only in its deepest part, located between the islands of Corsica and Capraia. The flow is generally northward, stronger between winter and late spring (mean velocity $0.15-0.2 \mathrm{~m} \mathrm{~s}^{-1}$ ), and weaker during summer until late autumn (mean velocity $0.05-0.1 \mathrm{~m} \mathrm{~s}^{-1}$ ). This pattern undergoes noticeable variations of intensity and duration, mostly in the stronger flow period (Astraldi and Gasparini, 1992). To the north of Corsica, the ECC merges with the Western Corsica Current (WCC). The resulting current proceeds northward and then westward, becoming the socalled Northern Current, a geostrophic frontal system along the continental slope, dividing coastal waters from denser waters of the central Ligurian Sea (Millot and TaupierLetage, 2005).

The Mediterranean, as a whole, is considered an oligotrophic sea. The north-western Mediterranean (e.g. the Ligurian Sea), however, exhibits large areas of high chlorophyll values thanks to the upwelling in the central part of the basin induced by the cyclonic circulation, providing conditions for enhanced primary productivity and a classical spring bloom. On the other hand, the Tyrrhenian Sea only has intermittent spring blooms, i.e. characterized by significant interannual variability (D'Ortenzio and D'Alcalà, 2009). The region of the Corsica Channel has intermediate characteristics between these two adjacent biogeographic regions.

\section{Materials and methods}

\subsection{ADCP settings, data quality control and estimation of the mean volume backscatter strength}

Data on echo intensity and vertical velocity $(W)$ were collected with a Teledyne RD Instruments (RDI) WH Long Ranger $76.8 \mathrm{kHz}$ ADCP, an instrument that is used in a longterm deployment and has a wide profiling range. The ADCP has four beams, which emit sound signals and receive echoes. These are put at $90^{\circ}$ azimuthal increments to each other and pointing at $20^{\circ}$ to the instrument axis. The four beams work as transducers converting sound signals in electrical signals. The ADCP is placed in an upward-looking position (the beams emit sound towards the surface) and is moored at about $400 \mathrm{~m}$ of depth near the bottom (which is at $443 \mathrm{~m}$ of 
depth) of the Corsica Channel between Corsica and Capraia islands (position $43.03^{\circ} \mathrm{E}, 9.68^{\circ} \mathrm{N}$ ). The time series used for this study spans from 5 April 2014 to 26 November 2016. During the collecting period, the ADCP was recovered six times for maintenance; therefore, there are six interruptions (generally $<24 \mathrm{~h}$ ) in the time series. The time series of vertical velocity and echo intensity were collected with a temporal resolution of $2 \mathrm{~h}$, an ensemble value resulting in 45 or 60 pings on average (which means a sound pulse every 2.4 or 2 min, depending on the deployment configuration), and a vertical spatial resolution of $16 \mathrm{~m}$, which is the length of the depth cells (or bins) into which the vertical profile is subdivided. The blanking length, at which the instrument does not measure, is $7.04 \mathrm{~m}$ above the transducer. All details on the ADCP settings during the seven deployments are listed in Table 1.

While echo intensity data need additional processing, $W$ data did not need further handling, except for some data selection criteria and quality control considerations to discard the low-quality data (this was also applied to backscatter data). Given that the total bin number was set to 28 and considering the blanking length plus the bin size of $16 \mathrm{~m}$, there were at least four bins above the sea surface which were discarded. Also, the first bin closest to the transducers is not used because it may record erroneous data due to the time taken for transient acoustic waves to decay (Lane et al., 1999). Moreover, $R(\mathrm{~m})$, the slant range of relevant scattering layers along each beam, defined as (see Deines, 1999)

$R=\frac{B+\frac{(L+D)}{2}+[(N-1) \times D]+\frac{D}{4}}{\cos \theta} \times \frac{c}{c_{0}}$,

must satisfy $R<H \cos \theta$, where $B(\mathrm{~m})$ is the blank distance from transducers to the first bin; $L(\mathrm{~m})$ is the transmit pulse length; $D(\mathrm{~m})$ is the cell or bin length; $N$ is the number of the cell (bin number); the angle $\theta$ (in degrees) is the inclination of each beam with respect to the vertical axis of the instrument $\left(20^{\circ}\right) ; c\left(\mathrm{~m} \mathrm{~s}^{-1}\right)$ is the sound velocity for each bin (computed following IOC-SCOR-IAPSO, 2010), which depends on salinity (a nominal value of 38 has been used), temperature $\left({ }^{\circ} \mathrm{C}\right)$ and pressure $(\mathrm{dbar}) ; c_{0}$ is the sound speed in seawater used by the ADCP $\left(1475.1 \mathrm{~m} \mathrm{~s}^{-1}\right)$; and $H(\mathrm{~m})$ is the distance between the head of the ADCP and the surface (Teledyne RD Instruments, 2011). All $R$ values from the 20th bin upwards exceeded the $H \cos \theta$ threshold and were thus discarded. Only for data collected during the fourth deployment (the deepest one; see Table 1 ) did the $R$ values computed in the 20th bin not exceed the threshold and were not discarded. Thus, the $N$ maximum value is equal to 20 for the fourth deployment and 19 for all other deployments. To avoid tilt error, pitch and roll of the instrument must not exceed $15^{\circ}$, and the data collected when pitch and roll were higher than $15^{\circ}$ have been discarded as well (Teledyne RD Instruments, 2011). Only few data were discarded due to this criterion, mainly in late winter and early spring because of the strong currents that occur in this period of the year (Astraldi and Gasparini, 1992), which can cause the inclination of the entire mooring line. A last data selection criterion was the percent good (PG) that had to be greater than $90 \%$. PG is a measure of the percentage of pings accepted to obtain the ensemble value of vertical velocity or echo intensity. Given all these constraints, ADCP gives information on DVM in a layer between about 70 and $390 \mathrm{~m}$. All considerations that will be made in the following need to take into account that there is a lack of information concerning zooplanktonic biomass and migration in the very surface layer and in the $50 \mathrm{~m}$ above the bottom.

To express the measured quantities in sound backscattered energy instead of echo intensity (which is measured in counts), first the mean volume backscatter strength (MVBS), measured in $\mathrm{dB} \operatorname{re}(4 \pi \mathrm{m})^{-1}$, is calculated as described in Deines (1999):

$$
\begin{aligned}
\mathrm{MVBS} & =C+10 \log _{10}\left[\left(T_{x}+273.16\right) R^{2}\right] \\
& -L_{\mathrm{DBM}}-P_{\mathrm{DBM}}+2 \alpha R+K_{\mathrm{c}}\left(E-E_{\mathrm{r}}\right),
\end{aligned}
$$

where $C$ is a constant factor specific to the ADCP model used $(\mathrm{dB}) ; T_{x}$ is the temperature detected at the transducer $\left({ }^{\circ} \mathrm{C}\right)$; $R$ is the slant rage (m) as defined by Eq. (1); $L_{\mathrm{DBM}}$ is the

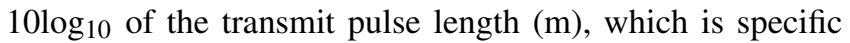
for each deployment; $P_{\mathrm{DBM}}$ is the $10 \log _{10}$ of the transmit power, specific for this ADCP model $(24 \mathrm{~W}) ; \alpha\left(\mathrm{dB} \mathrm{m}^{-1}\right)$ is the coefficient of sound absorption in seawater (Fisher and Simmons, 1977) at the specific bin depth and depends on the frequency of the sound pulse $(76800 \mathrm{~Hz}$ in this case), temperature $\left(T_{x}\right)$ and pressure; $K_{\mathrm{c}}$ converts counts in decibels and is defined by Eq. (3) (Heywood, 1996); $E$ is echo intensity (counts) calculated by averaging echo intensity detected by the four beams; and $E_{\mathrm{r}}$ is the noise value, i.e. the echo intensity detected by the instrument when there is no signal (50 counts in this case). The formula to compute $K_{\mathrm{c}}$, which appears on the right-hand side of Eq. (2), is given in Eq. (3):

$K_{\mathrm{c}}=\frac{127.3}{T_{x}+273}$.

To be used in Eq. (2) $R$ must not be less than $\pi R_{0} / 4$ (Deines, 1999 ), with $R_{0}$ (Rayleigh distance) being $1.3 \mathrm{~m}$ for this specific ADCP model. Following Deines (1999), the equation to compute the term $2 \alpha R$ is Eq. (4):

$2 \alpha R=\frac{2 \alpha_{\mathrm{p}} B}{\cos (\theta)}+\sum_{n=1}^{b} \alpha_{n}$,

where $\alpha_{\mathrm{p}}\left(\mathrm{dB} \mathrm{m}^{-1}\right)$ is the sound absorption at the depth of the profiler; $b$ is the last bin number; and $\alpha_{n}=2 \alpha D / \cos (20)$ is the sound absorption for each cell.

All parameters are summarized in Table 1.

\subsection{CTD data}

During servicing, between one deployment and the following one (see dates in Table 1), CTD casts are regularly performed 
Table 1. Deployment characteristics: the depth $-400 \mathrm{~m}$ is a nominal depth, while -395 and $-411 \mathrm{~m}$ are mean values from the continuous record of the ADCP pressure sensor; the blank is the distance between the transducer and the first bin; deployments 1 and 4 had a slow subsidence of $50 \mathrm{~cm}$ in $234 \mathrm{~d}$ and $30 \mathrm{~cm}$ in $102 \mathrm{~d}$.

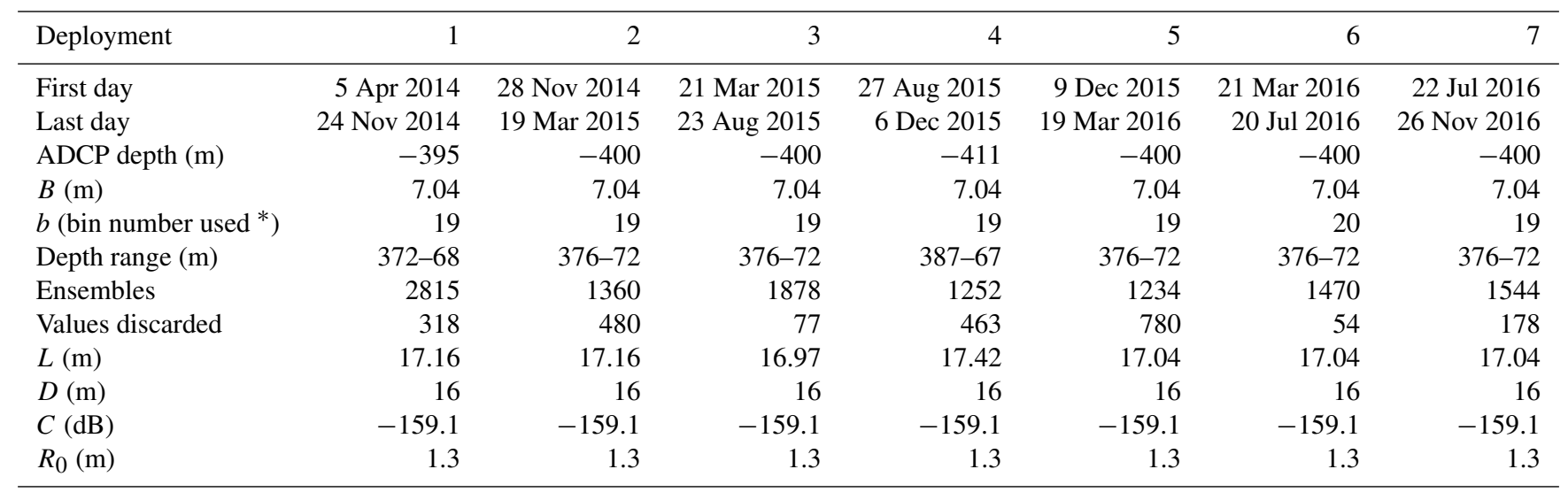

* Out of 28 .

from surface to bottom. These 6-monthly data are useful to provide information on the stratification and the depth of the chlorophyll maximum (the so-called deep chlorophyll maximum, or DCM) for the duration of the experiment. Time pressure, conductivity, temperature, dissolved oxygen concentration and chlorophyll fluorescence were measured with a CTD-rosette system consisting of a CTD SBE 911plus, a WET Labs fluorescence sensor and a General Oceanics rosette. The CTD probes were calibrated before and after each cruise (dissolved oxygen and salinity also during each cruise). Maintenance operations and CTD casts were done from the Italian vessels R/V Urania and R/V Minerva Uno.

In addition, a profiling buoy system for real-time data transmission was mounted on the mooring from 28 November 2014 to 20 March 2015. The system is composed of two units: (i) a profiling buoy, carrying a CTD sensor (with temperature, salinity, oxygen and chlorophyll fluorescence sensors) and an iridium antenna, and (ii) an underwater winch. Both units are provided with acoustic remote transceivers to communicate with each other and with a deck unit. The profiling system is moored at $190 \mathrm{~m}$ of depth on the mooring line, and it has been set to perform an upcast CTD profile from $190 \mathrm{~m}$ to the surface once a day. Conversely to CTD casts, which are only snapshots of the thermohaline conditions on a specific day at a certain time, these data give daily information on the whole upper layer for several months. A previous deployment in 2013 is extensively described in Aracri et al. (2016).

\subsection{Zooplankton net samples}

The backscatter strength and vertical velocity data collected by ADCP were complemented by data on zooplankton community composition, obtained from two samples retrieved in the Corsica Channel with a net of $1.13 \mathrm{~m}$ diameter and
$200 \mu \mathrm{m}$ mesh size. Some undersampling is possible since large organisms can avoid nets with a small mesh size (Moriarty et al., 2013). One net tow was done at the mooring location (sample no. 1; 24 August 2015 at 08:37 UTC; bottom depth $443 \mathrm{~m}$ ) while the mooring was recovered for maintenance, and the second one was done about $6.5 \mathrm{~km}$ to the west (sample no. $2 ; 43.03^{\circ} \mathrm{N}, 9.60^{\circ} \mathrm{E} ; 24$ August 2015 at 10:00 UTC; bottom depth $234 \mathrm{~m}$ ) from the Italian vessel R/V Minerva Uno. As the sampling net did not reach the bottom (it remains 10-15 $\mathrm{m}$ above it), some organisms might not be sampled if they stay in the deepest layer close to the bottom, a common behaviour, especially during the day (Vinogradov, 1997). Indeed, populations of many pelagic species extend into hyperbenthic and benthopelagic environments within a few metres from the sea floor, where there may be a significant accumulation of zooplanktonic biomass during the day in specific seasons (Mauchline, 1998 and references therein). The two stations were sampled for the taxonomic and quantitative characterization of mesozooplanktonic communities. Samples were collected by vertical hauls, almost from the bottom to the surface, using a standard Indian Ocean net equipped with flowmeters for filtered-volume calculation and preserved with borax-buffered formaldehyde. Taxonomic and quantitative zooplankton determinations were performed using a Zeiss stereomicroscope at the lowest possible taxonomic level (species level for copepods and cladocerans) on a representative subsample, while the total samples were analysed for rare species determination.

\subsection{Additional ancillary data and statistical methods}

Additional environmental parameters were used for this study to investigate a potential correlation with vertical migration and the amount of zooplanktonic biomass in the Corsica Channel and to explain what drives them. 
These parameters are sunrise and sunset time (using the script suncycle.m; downloaded from http://mooring.ucsd. edu/software/matlab/doc/toolbox/geo/suncycle.html, last access: 20 May 2019), surface chlorophyll $a$ concentration (Chl $a$ in $\mathrm{mg} \mathrm{m}^{-3}, 1 \mathrm{~km}$ resolution, $8 \mathrm{~d}$ averages) in the area of the mooring (downloaded for the domain latitude $43.0097^{\circ} \mathrm{N}, \quad 9.4^{\circ} \mathrm{E}<$ longitude $<9.8^{\circ} \mathrm{E}$ ) computed via regional algorithms (Volpe et al., 2007) and retrieved from the COPERNICUS Marine Environment Monitoring Service or CMEMS (product name OCEANCOLOUR_MED_CHL_L4_REP_OBSERVATIONS_009_

078; downloaded from http://marine.copernicus.eu/ services-portfolio/access-to-products/, last access: 20 May 2019), and the moon phases (retrieved from https://aa.usno.navy.mil/data/docs/MoonPhase.php, last access: 20 May 2019) to estimate the potential effect of moonlight on vertical migration patterns.

Two statistical analyses were applied to the MVBS and $W$ datasets: a spectral analysis using the fast Fourier transform (FFT) and a lagged cross-correlation analysis. FFT was applied to the datasets after data gaps were filled using a partial differential equation method to identify the most relevant oscillations in the vertical migration patterns and observe the peaks with the highest amplitude at both high and low frequencies. Low-frequency peaks were determined after applying a low-pass filter (frequencies $<5 \times 10^{-7} \mathrm{~Hz}$, which is approximately $23 \mathrm{~d}$ ). The lagged cross-correlation analysis between MVBS and Chl $a$ was done to investigate if in this area the phytoplankton biomass is a relevant driver for blooms of secondary producers (for which MVBS is considered to be a proxy). The time series have been pre-whitened (a smoothing and a detrending was applied) to remove autocorrelation before assessing their cross-correlations, and the $95 \%$ confidence bounds have been computed.

\section{Results and discussion}

The data collected by the ADCP are used to define the temporal and spatial variability of zooplankton DVM and zooplanktonic biomass distribution patterns during the investigated period. Additional environmental data are derived from CTD casts and satellites in order to improve knowledge about what might possibly drive zooplankton behaviour and blooms, while the taxonomic analysis of the zooplankton net samples is used to describe the community structure.

\subsection{Thermohaline characteristics within the channel}

Seasonal variability of thermohaline characteristics in the area is evidenced by marked differences between the stratified water column in summer and unstratified water column in winter. CTD data collected during mooring maintenance allow us to investigate this behaviour (Fig. 2a-d). CTD casts in March 2015 and 2016 are representative of the end- ing phase of winter conditions, with homogeneously stratified temperature vertical profiles and a relatively higher level of dissolved oxygen at depth as a result of wintertime open ocean convection. Chlorophyll fluorescence shows maxima in the surface layer (at 20-30 m) approaching the spring phytoplanktonic bloom period and a weak secondary relative maximum in correspondence with an oxygen maximum at depth (200 m in March 2015 and $250 \mathrm{~m}$ in March 2016), possibly relict phytoplanktonic populations transported downward by vertical mixing or photosynthetic picoplankton able to use the wavelengths and low light levels that are characteristics of this depth. In summer the water column is well stratified, with the development of a sharp thermocline in the uppermost 20-40 m, lower surface oxygen contents and a DCM at about $100 \mathrm{~m}$ (Fig. 2d). In fall, the surface layer undergoes a progressive cooling toward winter, the thermocline being at about 50-60 $\mathrm{m}$ and the DCM becoming weaker and shallower $(60 \mathrm{~m})$. Salinity below the interface between AW and IW $(>200 \mathrm{~m})$ is generally homogeneous, except in winter when this interface is deeper (Fig. 2b).

The evolution through winter can be followed by means of the daily data time series collected by the moored profiler (profiling range between 0 and $190 \mathrm{~m}$ ) that was in place from November 2014 to March 2015 (Fig. 2e-g). Progressive cooling of the water column continues until late January (Fig. 2e), when fully mixed conditions are eventually met. Conversely, dissolved oxygen (Fig. 2f) and chlorophyll fluorescence (Fig. 2g) gradually increase in the whole upper layer while approaching the spring season.

\subsection{Acoustic backscatter and vertical velocity}

Vertical velocities along the water column and backscatter strength are analysed to identify zooplankton motions and biomass variations. Since with a sampling period of $2 \mathrm{~h} W$ values are very low and do not represent the actual velocity of these organisms, they are nevertheless used to provide insights on the net direction of motion (up or down) according to the hour of the day, season and depth range. Additionally, without the necessary net samples that would allow for a proper calibration, MVBS is considered an indirect and qualitative proxy for zooplanktonic biomass. In the following, we will use "zooplanktonic biomass" when referring to qualitative information inferred from MVBS data.

The data collected over the entire period of the seven deployments (April 2014-November 2016) are shown in Fig. 3. MVBS is computed with Eq. (2) for each bin, while its anomalies (Fig. 3a) are obtained by subtracting from each MVBS profile the average MVBS profile of the entire period. All considerations that follow do take into account the lack of information concerning MVBS and $W$ in the very surface layer and in the $50 \mathrm{~m}$ above the bottom.

MVBS anomalies (Fig. 3a) clearly present periodic oscillations, with notably higher than average values approximatively between November-December and April-May, denot- 

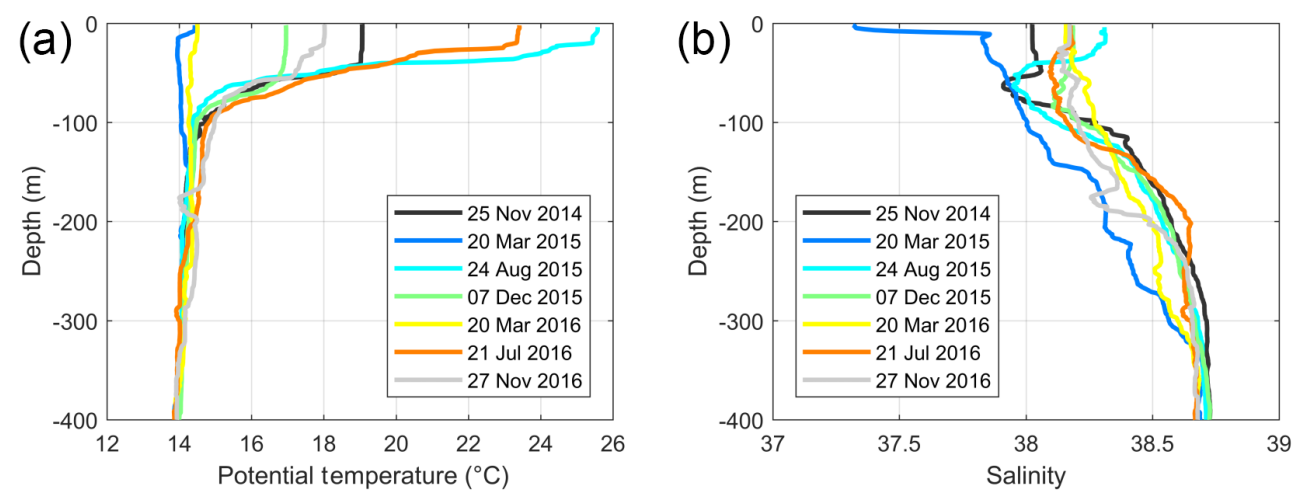

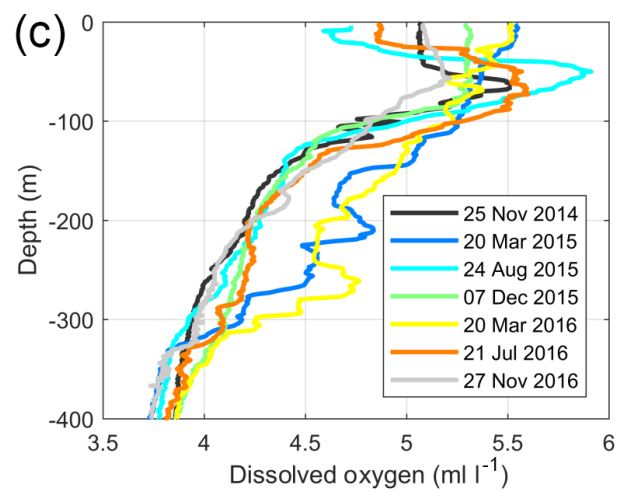

(e)

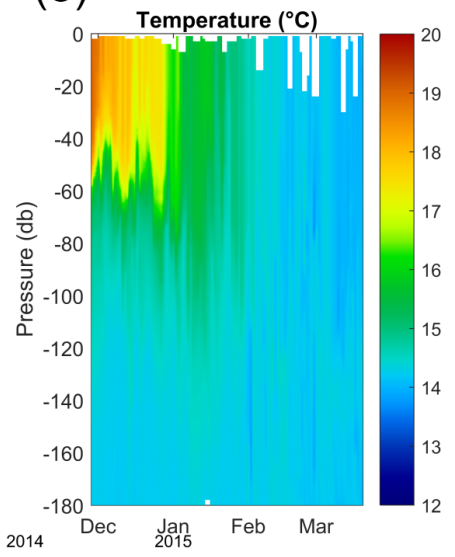

(f)

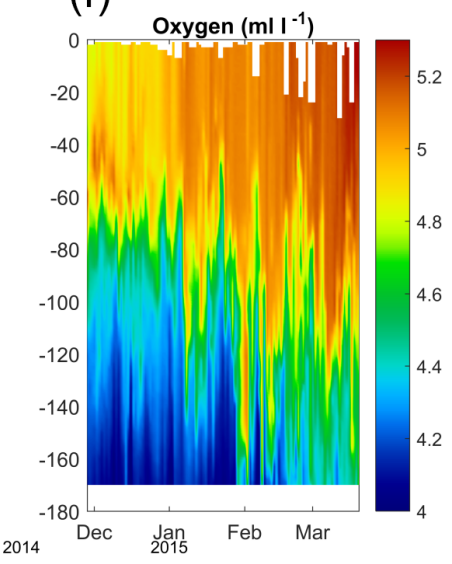



(g)

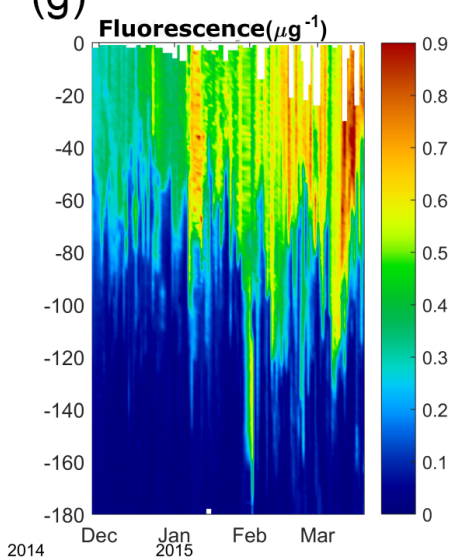

Figure 2. (a-d) Vertical profiles of potential temperature, salinity, dissolved oxygen and chlorophyll fluorescence, respectively, from CTD casts carried out during servicing at the mooring location; since density is controlled by temperature the thermocline depth is essentially equivalent to the pycnocline depth. (e-f) Daily vertical profiles of temperature, dissolved oxygen and chlorophyll fluorescence, respectively, from November 2014 to March 2015, as recorded by the moored profiler.

ing a zooplanktonic bloom that involves most of the investigated water column. High values in the upper part of the investigated water column associated with low values in the deeper part of the investigated water column are observed outside the zooplanktonic blooming periods. Since we use MVBS as a proxy for secondary production, the observed variability is probably linked to the primary production seasonality as well as to the alternation of stratified and mixing periods, as described earlier (Estrada et al., 1985). The peaks of the zooplanktonic blooming period in 2015 and in 2016 are slightly different, with 2015 presenting a prolonged and more intense increase in MVBS than 2016.

In Fig. 3a the daily cycle is not visible, and to show its features Fig. 3b-g represent the temporal evolution of MVBS and $W$ at selected depths (within the upper, intermediate and deep layers) as a function of the hour of the day (UTC) and with the times of sunset and sunrise (that change seasonally) superimposed. 
(a)

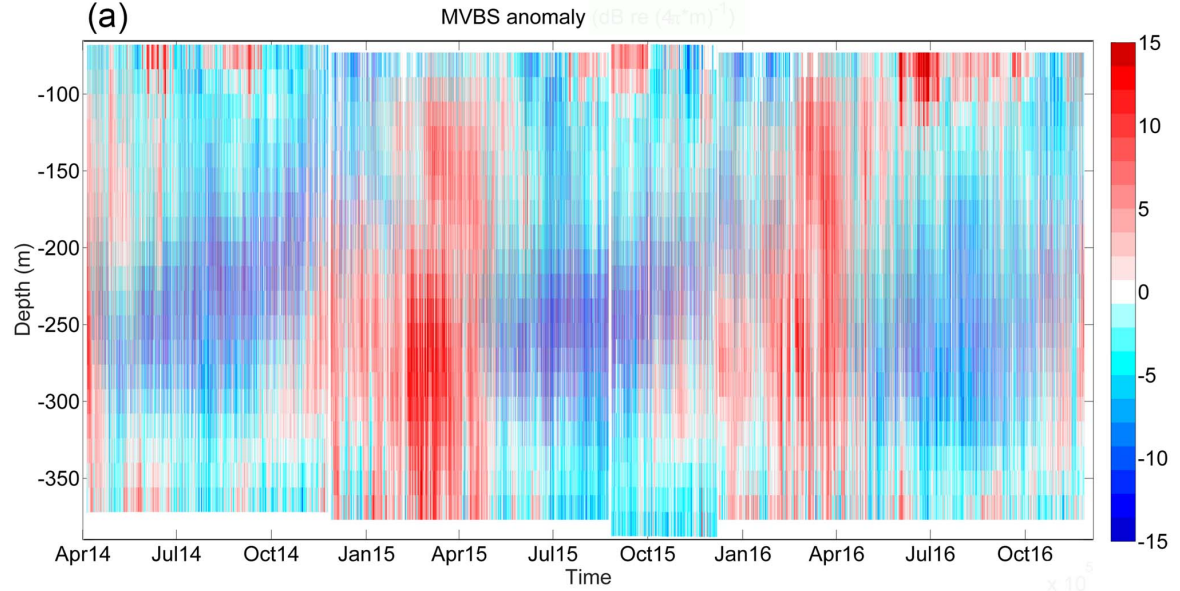

(b)

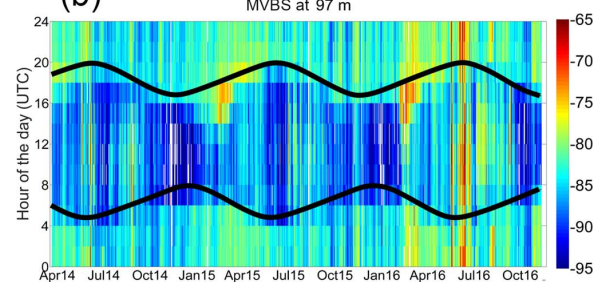

(d)
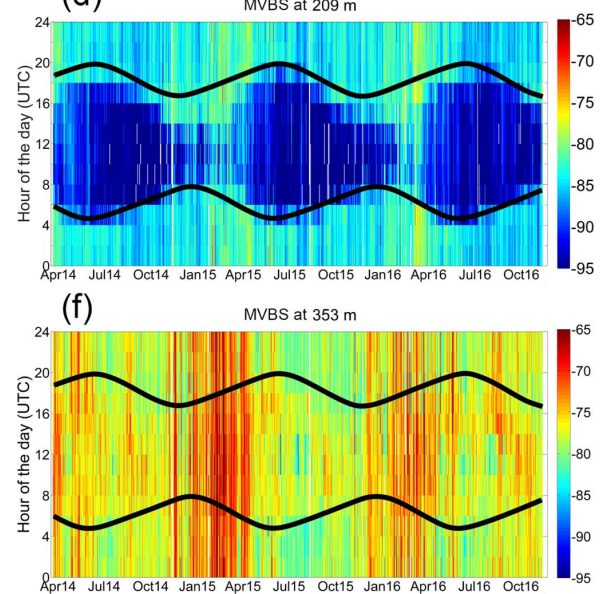

(c)

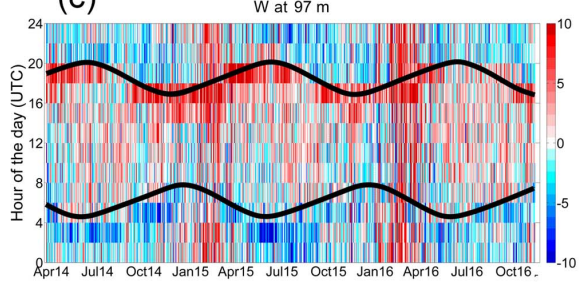

(e)



(g)

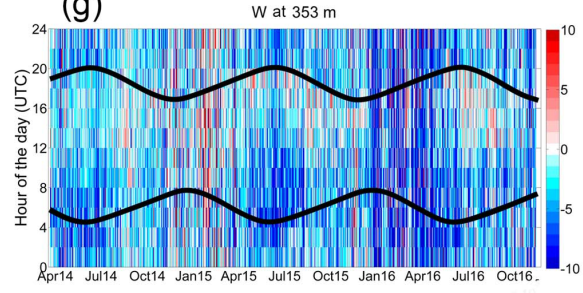

Figure 3. (a) Time series ( $2 \mathrm{~h}$ ) of vertical profiles of MVBS (mean volume of backscatter in $\mathrm{dB}$ re $(4 \pi \mathrm{m})^{-1}$ ) anomalies (referring to the mean profile of the entire dataset) from April 2014 to November 2016; (b-c) MVBS $\left(\mathrm{dB}\right.$ re $\left.(4 \pi \mathrm{m})^{-1}\right)$ and $W\left(\mathrm{~mm} \mathrm{~s}^{-1}\right)$ variations in time as a function of the hour of the day (UTC) at $97 \mathrm{~m}$, with the time of sunset and sunrise superimposed (black lines); (d-e) same as (b-c) but at $209 \mathrm{~m} ;(\mathbf{f}-\mathbf{g})$ same as $(\mathbf{b}-\mathbf{c})$ but at $353 \mathrm{~m}$.

In the upper layer (bin centred at $97 \mathrm{~m}$ ) MVBS is clearly higher during the night and lower during the day (Fig. 3b). Summer 2016 behaves differently compared to summer 2015, with very high values persisting night and day (JuneJuly 2016). During the zooplanktonic blooming periods, MVBS peaks from 2 to $4 \mathrm{~h}$ before sunset. $W$ in the upper layer (Fig. 3c) is clearly directed upward (positive $W$ ) at sunset and downward (negative $W$ ) before dawn for the whole duration of deployment. This is consistent with the classical picture of nocturnal DVM. In February-March (2015 and
2016) there are very strong positive values persisting night and day.

In the intermediate layer (bin centred at $209 \mathrm{~m}$ ) MVBS has a more pronounced daily pattern than in the upper layer (Fig. 3d), with nocturnal high backscatter strength and diurnal MVBS minima. The summer 2016 persistently high values found in the upper layer are absent at mid-depth. Also, here the MVBS starts to increase from 2 to $4 \mathrm{~h}$ before sunset, especially during the zooplanktonic blooming period, as observed in the upper layer. The patterns of descent and ascent (Fig. 3e) are clearly observed throughout the whole pe- 
riod and closely follow the seasonality of sunrise and sunset times. Downward velocities at sunrise are much stronger than in the upper layer and also than the upward velocities at sunset. In summer (2015 and 2016, less in 2014) there is a strong upward motion just after sunrise, which is consistent with twilight or reverse migration patterns.

In the deep layer (bin centred at $353 \mathrm{~m}$ ) MVBS is quite high during the whole experiment (Fig. 3f), with small differences between day and night. We discarded the possibility of this layer being a nepheloid layer after investigating historical turbidity data (from a transmissometer mounted on the CTD-rosette system) at the same location (above 410 $420 \mathrm{~m}$ turbidity levels were always low). Overall, except during the zooplanktonic blooming periods, it appears that diurnal MVBS values are slightly higher than nocturnal values of MVBS, indicating that some organisms migrate from higher levels down to high depths during the day. However, in the deep layers the migration is hardly seen (Fig. 3g). It is likely that this layer is occupied by non-migrating organisms or organisms that have a reduced migration. During the zooplanktonic blooming period in winter-spring, MVBS reaches the highest levels, with no difference between day and night and with 2015 showing a more intense peak than 2016. At this depth, $W$ (Fig. $3 \mathrm{~g}$ ) is not clearly correlated with sunlight, with prevalent negative velocities occurring at almost all times. Downward motions are stronger in 2016 from late winter to spring, in summer 2014 and 2015 during night, and in the hours before and after sunrise. Upward motions are very weakly correlated with sunset and slightly increase from noon to sunset during some periods and during the 2015 zooplanktonic blooming period.

To investigate in more detail the seasonal variability of MVBS along the water column, as well as the different patterns of MVBS and $W$ during the zooplanktonic blooming period (approx. from December to April, defined as the period when the integrated MVBS values stay above a certain threshold value) and the non-blooming period (approx. from May to November, defined as the period when the integrated MVBS values stay below that threshold), these parameters are shown as a function of depth, month of the year (monthly means in Fig. 4a-b) and time of the day (Fig. 4c-f).

In particular, it is observed that the highest values of monthly mean MVBS occur between November-December and April (Fig. 4a), which corresponds to the zooplanktonic blooming period and with a peak that involves the whole water column in March. The associated standard deviation (Fig. 4b) shows that the zooplanktonic blooming period is also the one with less variability. During the rest of the year (the non-blooming period), MVBS is very low, especially at mid-depth (between 150 and $300 \mathrm{~m}$ ), while it presents a higher degree of interannual variability, as evidenced by the standard deviation (particularly high between 200 and $330 \mathrm{~m}$ from June to October). Such an MVBS seasonal pattern is likely to be the response of zooplankton to both the different thermohaline conditions of the water column
(MVBS increases when stratification is weaker and the thermocline is almost absent; see Sect. 4.1) and the seasonality of phytoplankton blooms and DCM position (see Sect. 4.1 and the following Sect. 4.4 for details). During summerautumn, when stratification is stronger and the DCM is deeper (Fig. 2d), MVBS maxima are split into two layers (Fig. 4a): a shallower one and a very deep one, which is likely to be due to the presence of two zooplanktonic communities with different depth-based habitat preferences (as found also by Heywood, 1996, and Pinot and Jansà, 2001). This is a consistent pattern, as denoted by the mostly low standard deviations in these two layers during the non-blooming period (Fig. 4b). Since the ADCP measurements miss the first tens of metres of the water column, the summertime increase in MVBS at 70-100 m might also be a consequence of the cyclic summer descent (due to the increase of irradiance) of a group of epi-zooplanktonic organisms that during the rest of the year find food and optimal light and temperature conditions in more superficial waters. It has been previously reported that in the western Mediterranean during summer the zooplanktonic biomass maximum at daytime is concentrated around the same depth as the DCM (in the range from 70 to $90 \mathrm{~m}$, which is close to the upper limit of the present observations), while at night this maximum rises up to less than $20 \mathrm{~m}$ (Alcaraz, 1985).

The different DVM patterns during zooplanktonic blooming and non-blooming periods are shown in Fig. $4 \mathrm{c}-\mathrm{d}$ and in Fig. 4e-f, respectively. During a first analysis, sunlight is easily identifiable as the most important driver of DVM during both non-blooming and blooming periods.

During the non-blooming period MVBS shows a bimodal distribution, with high zooplanktonic biomass levels being evident in both the upper layer (above $120 \mathrm{~m}$ ) and in the bottom layer (below $330 \mathrm{~m}$ ); there are very low levels at mid-depth (Fig. 4c), a feature that is also evident in the seasonal full-depth analysis in Fig. 4a. In the course of the day the mid-depth minimum becomes thicker, expanding mainly towards the deeper levels (Fig. 4c); although thinner, the MVBS minimum layer also persists during night, occupying the depth range of $150-250 \mathrm{~m}$ as opposed to the 120 $350 \mathrm{~m}$ range occupied during the day (with maximum thickness at midday). In the upper layer MVBS is higher during night than during the day, while at depth it maintains approximately a constant level, with only a slight increase the during day. Vertical motion is directed downward along the whole water column during night, with a maximal intensity at dawn (04:00-06:00 UTC), and is bidirectional during the day, with a maximum upward intensity at dusk (16:0018:00 UTC) above $300 \mathrm{~m}$ (Fig. 4d).

During the blooming period the bimodal distribution of MVBS is weaker (Fig. 4e), with zooplanktonic biomass in the upper layers exhibiting lower levels compared to both the deep layer and to the upper layer during the non-blooming period (Fig. 4c). However, it has to be considered that no data are available for the most superficial bins for this pe- 


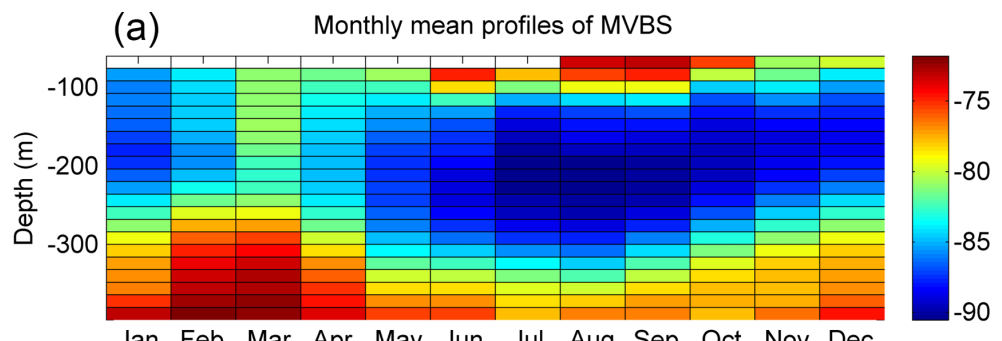

(b) Standard deviation profiles of monthly mean MVBS

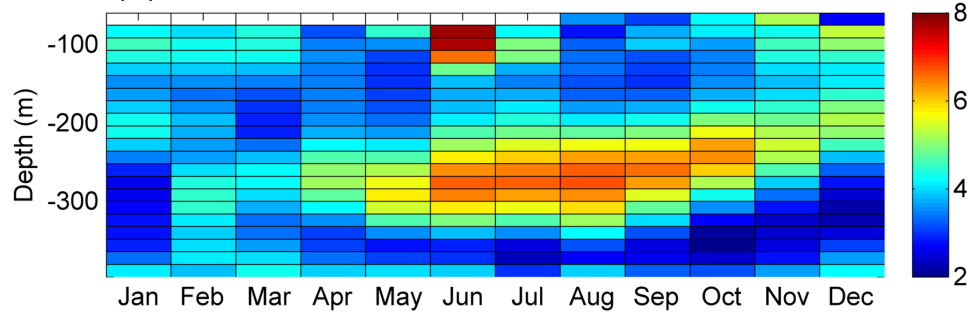

(c)

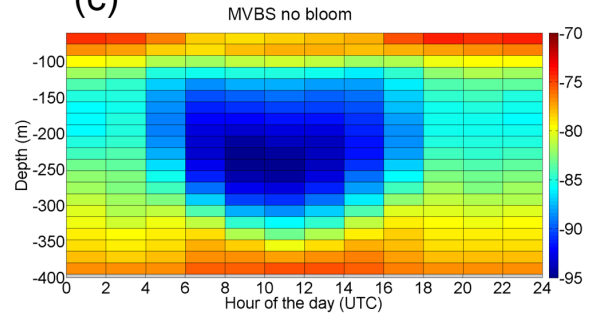

(e)

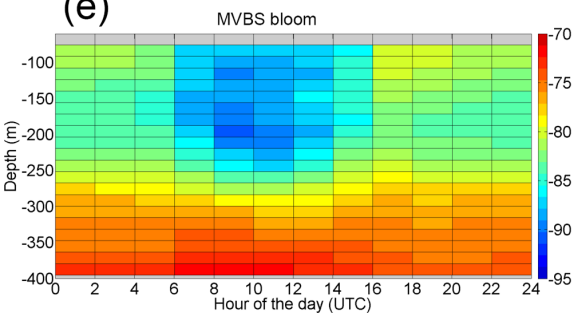

(d)

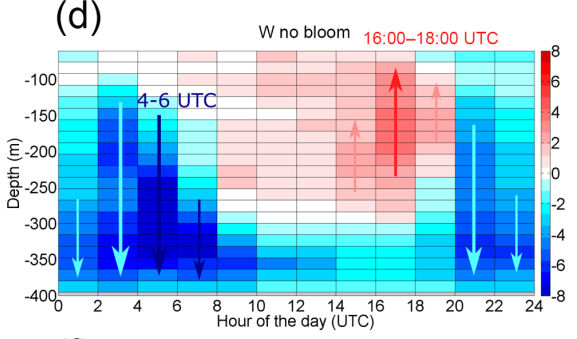

(f)

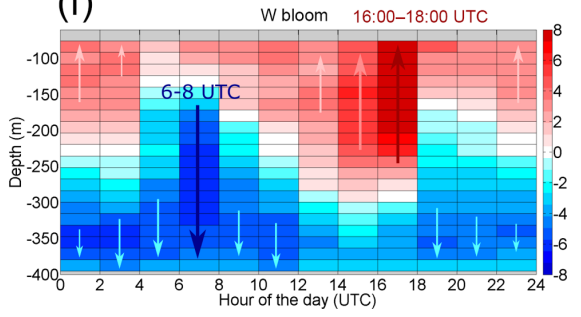

Figure 4. Monthly mean (a) vertical MVBS profiles $\left(\mathrm{dB}\right.$ re $\left.(4 \pi \mathrm{m})^{-1}\right)$ and their standard deviation (b); (c-d) mean MVBS $\mathrm{dB}$ re(4 $\left.\pi \mathrm{m}^{-1}\right)$ and $W\left(\mathrm{~mm} \mathrm{~s}^{-1}\right)$ during zooplanktonic non-blooming periods (approximately between May and November) as a function of depth (m) and hour of the day; (e-f) mean MVBS $\left(\mathrm{dB}\right.$ re $\left.(4 \pi \mathrm{m})^{-1}\right)$ and $W\left(\mathrm{~mm} \mathrm{~s}^{-1}\right)$ during zooplanktonic blooming periods (approximately between December and April) as a function of depth (m) and hour of the day. Bluish and reddish arrows in (d) and (f) indicate main downward and upward motions, respectively. The time span of the most evident downward and upward events is given in (d) and (f).

riod (as a consequence of the quality control applied to the raw data; see Sect. 3.1), so it remains questionable whether more zooplanktonic biomass is found above these levels or not. During the blooming period the MVBS minimum layer is thinner and resides at shallower depths compared to the non-blooming period (80-270 m instead of 120-350 m depth range). In addition, the day-to-night differences of this layer are less pronounced during this period (Fig. 4e). Vertical motion during the blooming period (Fig. 4f) is directed downward at 06:00-08:00 UTC (a bit later because of later sunrise times during the blooming period), while the upward migration occurs mostly at 16:00-18:00 UTC and is more intense than during the non-blooming period (Fig. 4d). Thus, it ap- pears that in the investigated water column active upward motion is intensified during the blooming period and that zooplanktonic biomass in the upper layers is relatively lower than during the non-blooming period.

These outcomes are consistent with the hypothesis (Hardy and Gunther, 1935; Huggett and Richardson, 2000) that when food availability is high (as occurs during phytoplankton blooms, which will be discussed in Sect. 4.4), the migration is intensified because herbivorous zooplankton feeds enough during the night to compensate for the effects of not feeding during the day by descending into deeper layers in order to hide from visual predators. In contrast, when food availability is scarce (non-blooming periods), those organ- 
isms have to take the risk of predation by staying in the upper layers during the day to compensate for the shortage of food sources. However, it needs to be taken into account that the observed differences during the two periods may also be explained by a community shift and other environmental factors, e.g. stratification, thermocline depth and position of the DCM. Indeed, according to Angel (1968) and Ringelberg (2010) a strong thermocline has a negative effect on vertical migration, which implies that the bimodal distribution and the reduced vertical migration observed during the non-blooming period can also be attributed to the strong thermoclines that develop during late spring to summer (Fig. 2a and Sect. 4.1).

As has been described and depicted in Fig. 3b-g and Fig. $4 \mathrm{c}-\mathrm{f}$, nocturnal migration with a $24 \mathrm{~h}$ cycle (a circadian cycle conditioned by sunlight) is the most evident type of migration in the study area. Yet some other migrating cycles could be hidden. For instance, from Fig. $4 \mathrm{~d}$ and $\mathrm{f}$, it appears that there is a strong descent after sunset at 20:0022:00 UTC during the non-blooming period (less strong at 18:00-20:00 UTC in the blooming period), which could be identified as a signature of reverse migration.

In order to identify other migration patterns, a fast Fourier transform (FFT) is applied to the dataset of MVBS and $W$ (Fig. 5a and b, respectively). The spectral analysis is also applied to the low-pass-filtered time series to identify lowerfrequency signals (Fig. 5c and d, respectively, for MVBS and $W$ ).

It is clearly evident that MVBS and $W$ have the same peak frequencies at periods shorter than $1 \mathrm{~d}$, although with differences in amplitude (Fig. 5a-b). The most evident peak is at $24 \mathrm{~h}$, as expected by the prevalent nocturnal DVM pattern, as well as by the less frequent reverse migration. The amplitude of the peak is the highest at mid-depth (bin centred at $209 \mathrm{~m}$ ), while it decreases both upward and downward (at a minimum within the bin centred at $353 \mathrm{~m}$ ). This difference between layers has already been observed while discussing Fig. 3b-f. At $12 \mathrm{~h}$ there is a prominent peak for both MVBS (at 97 and $209 \mathrm{~m}$, but hardly visible at $353 \mathrm{~m}$ ) and $W$ (at all three depths), which might be due to some zooplanktonic groups that undertake reverse migration: although this migratory behaviour has a $24 \mathrm{~h}$ cycle as well and occurs during sunset (descent) and sunrise (ascent), as does nocturnal migration, if reverse and nocturnal migration both occur this can produce a signal at $12 \mathrm{~h}$ (the time lapse between two consecutive ascending events and two consecutive descending events is around $12 \mathrm{~h}$ ). The fact that the $12 \mathrm{~h}$ peaks in MVBS are less intense than the $24 \mathrm{~h}$ peaks suggests that reverse migration does not take place throughout the year or does not involve a large number of organisms. This would also explain why reverse migration was not evident in Fig. 3b-g. The $12 \mathrm{~h}$ peak could also be due to twilight migration, as suggested by Bozzano et al. (2014) and Picco et al. (2016). The other peaks at $8 \mathrm{~h}, 6 \mathrm{~h}$ (both very strong at $209 \mathrm{~m}$, almost absent at $353 \mathrm{~m}$ ) and $4.75 \mathrm{~h}$ (not visible at $353 \mathrm{~m}$ ), in both MVBS and $W$ spectra, are quite difficult to attribute to a specific migrational behaviour and could possibly be due to different groups performing different patterns of twilight migration; $4.75 \mathrm{~h}$ is consistent with the mean time lapse between midnight descent and sunrise descent. Indeed, in Fig. $4 \mathrm{~d}$ ( $W$ during the non-blooming period) it is possible to see ascending motions right after the descent at sunrise, followed by upward velocities at sunset, i.e. $8 \mathrm{~h}$ later on average. The low amplitude of these peaks again suggests that twilight migration also does not take place throughout the year or does not involve a large number of organisms.

Some low-frequency peaks appear in the low-pass-filtered MVBS and $W$ time series (Fig. 5c-d), although they are not very pronounced (28-30 d, which might indicate a cycle connected with moon phases; 80-96 d, which might relate to the alternation of seasons; $160-193 \mathrm{~d}$, possibly reflecting the broader periods of zooplanktonic blooming and nonblooming; $322 \mathrm{~d}$, i.e. an almost 1-year period, which might correspond to the mean time lapse between two consecutive spring maxima and/or summer minima).

\subsection{Zooplanktonic community composition in summer 2015 and associated DVM patterns}

In order to describe the zooplankton community, two net samples collected in the study area in August 2015 are discussed in detail in the following, keeping in mind that these samples are snapshots of a diurnal situation in a specific summer and cannot give insights into the temporal variability of the community and that the vertical distribution is not resolved, with the samples being collected by integrated vertical tows. However, they are the sole ground-truth information that is available and it is therefore relevant to report here.

In the two stations, copepods were by far the most abundant group with $83 \% \pm 0.4$ of the total community, followed by other taxa, mainly represented by appendicularians and chaetognaths with $13 \% \pm 2.8$ and then by cladocerans with $4 \% \pm 3.2$. Both stations showed a very similar community dominated by a few species, mainly belonging to epipelagic copepods, with the two most abundant genera, i.e. Clausocalanus spp. and Oithona spp., accounting for more than $50 \%$ of the total abundance (Table 2). In the western and slightly shallower station (sample no. 2), the abundance of cladocerans was higher compared to the station at the mooring location (sample no. 1), as is evident from Table 2. The community is essentially composed of organisms that do not migrate significantly (Scotto di Carlo et al., 1984), which is consistent with the reduced migration during summer detected by ADCP (Fig. 4d). Most organisms found in the samples were smaller than the size detection limit in this configuration $(0.48 \mathrm{~cm})$, and therefore the ADCP detects them only in high-density aggregations.

To explore in more detail the DVM patterns that involve the sampled community, the evolution of MVBS anomalies around the time of the zooplankton sampling $( \pm 15 \mathrm{~d})$ is 

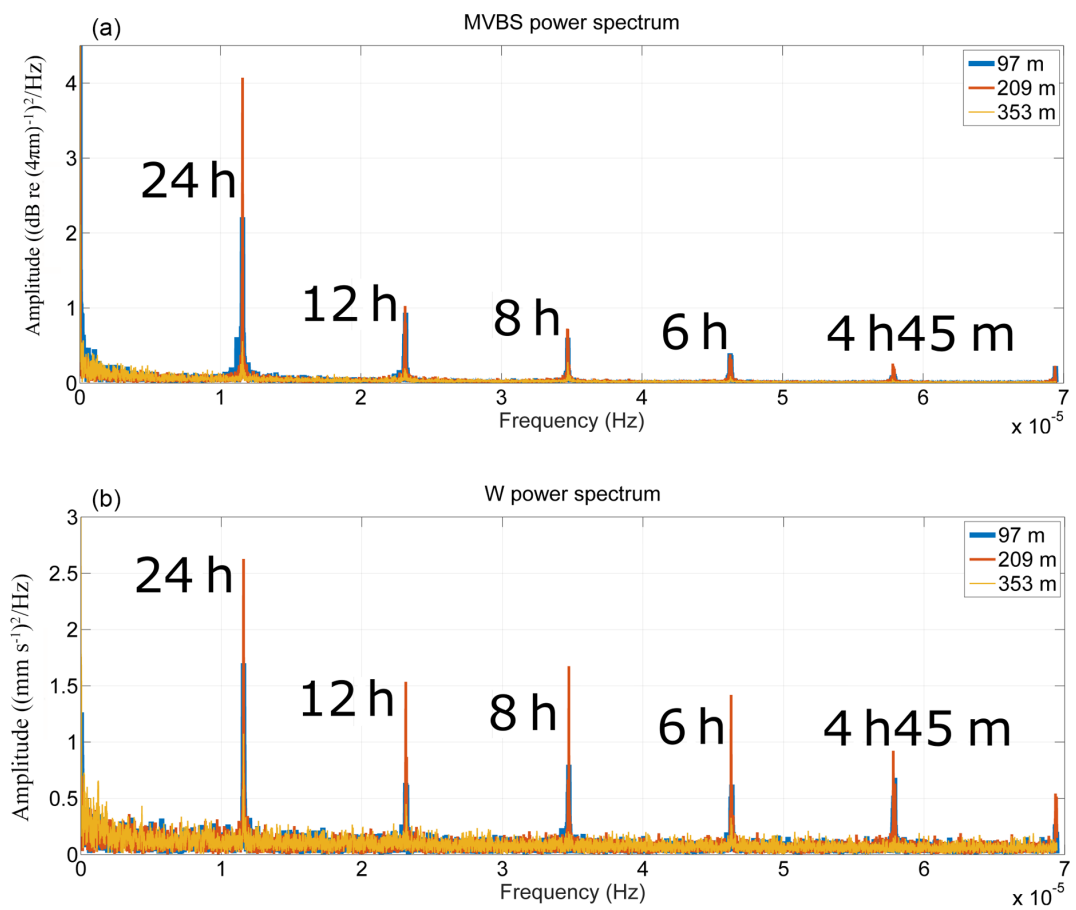

(c) MVBS low-frequency power spectrum
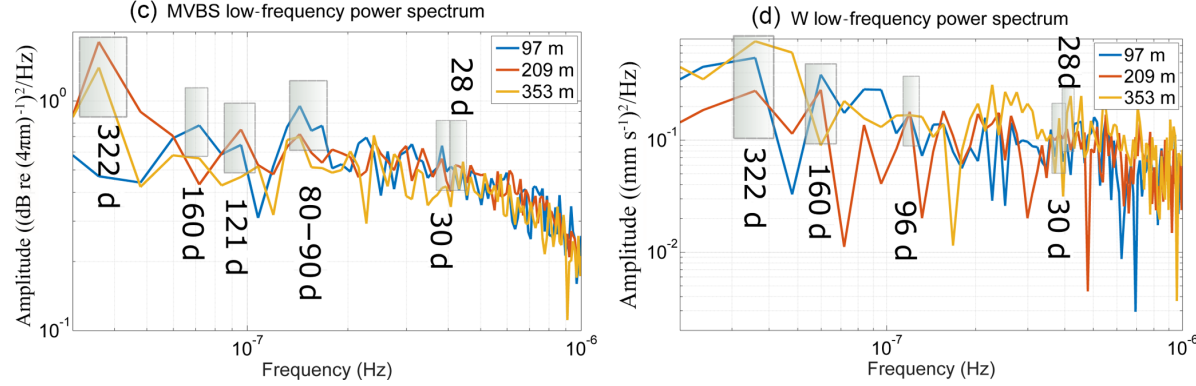

Figure 5. (a) Power spectrum of MVBS (high-frequency range) at three selected bins (97, 209, $353 \mathrm{~m}$ ); (b) same as (a) but for $W$. (c) Power spectrum of the low-passed MVBS time series (low-frequency range) at three selected bins (97, 209, $353 \mathrm{~m}$ ); (d) same as (b) but for $W$.

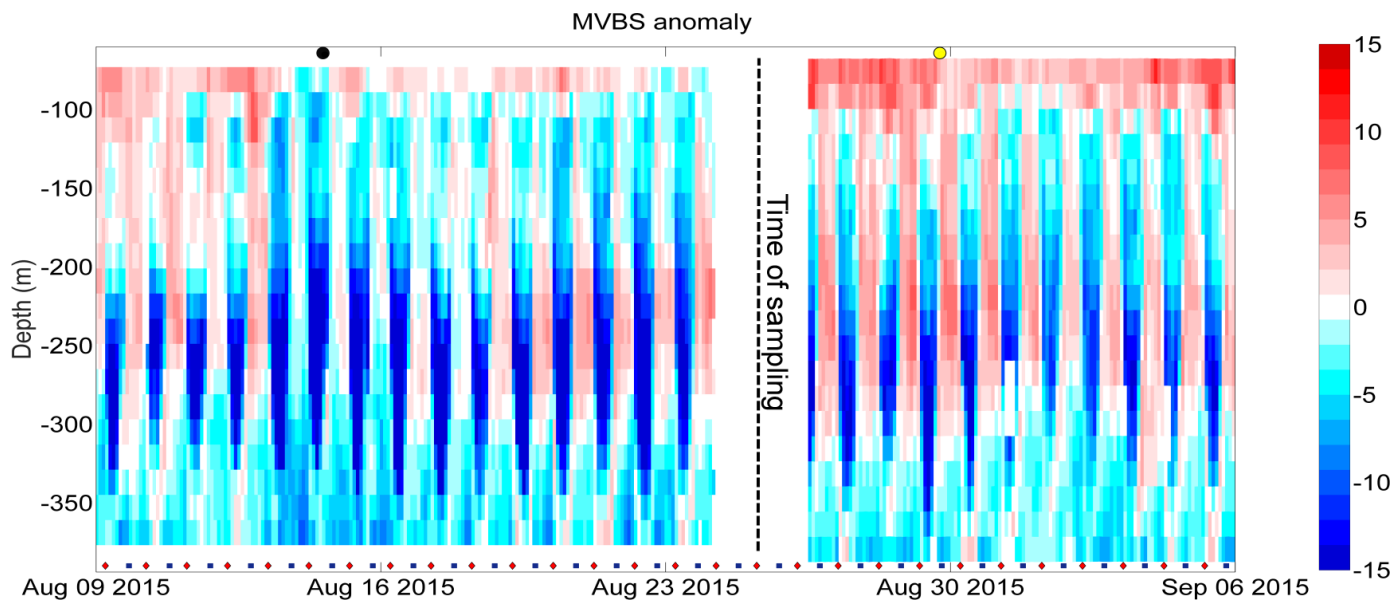

Figure 6. MVBS anomalies ( $\mathrm{dB}$ re $(4 \pi \mathrm{m})^{-1}$ ) between 9 August and 6 September 2015. The timing of new moon (black dot above the graph), full moon (yellow dot above the graph), sunrise (red diamond below the graph) and sunset (blue square below the graph) is indicated. 
Table 2. Contribution of the most abundant species and/or taxa at the two sampling sites in number of individuals ( $N$ ) per cubic metre of water (COP: copepods, CLA: cladocerans, OTH: other taxa).

\begin{tabular}{llrrr}
\hline Taxon & Group & $\begin{array}{r}N \text { per } \mathrm{m}^{3} \\
\text { sample no. 1 }\end{array}$ & $\begin{array}{r}N \text { per } \mathrm{m}^{3} \\
\text { sample no. } 2\end{array}$ & $\begin{array}{r}\text { Mean } \\
\%\end{array}$ \\
\hline Clausocalanus spp. & COP & 74.22 & 153.31 & $38.96 \pm 1.91$ \\
Oithona spp. & COP & 26.59 & 49.95 & $13.11 \pm 0.23$ \\
Appendicularia indet. & OTH & 8.22 & 12.60 & $3.56 \pm 0.59$ \\
Oncaea spp. & COP & 9.19 & 11.29 & $3.51 \pm 1.18$ \\
Paracalanus spp. & COP & 1.21 & 15.20 & $2.81 \pm 2.37$ \\
Chaetognatha & OTH & 6.77 & 8.69 & $2.65 \pm 0.80$ \\
Calocalanus spp. & COP & 3.14 & 11.29 & $2.47 \pm 0.96$ \\
Temora stylifera & COP & 6.77 & 7.58 & $2.46 \pm 1.00$ \\
Ctenocalanus vanus & COP & 5.56 & 8.69 & $2.44 \pm 0.37$ \\
Pleuromamma spp. & COP & 5.08 & 8.69 & $2.36 \pm 0.20$ \\
Corycaeus spp. & COP & 6.29 & 6.08 & $2.12 \pm 1.11$ \\
Nannocalanus minor & COP & 4.59 & 6.95 & $1.98 \pm 0.35$ \\
Pseudoevadne tergestina & CLA & 0.24 & 10.42 & $1.83 \pm 1.83$ \\
Evadne spinifera & CLA & 0.97 & 9.12 & $1.73 \pm 1.34$ \\
\hline
\end{tabular}

shown in Fig. 6. Around new moon MVBS shows lower levels than around full moon, especially in the shallower bins, which is consistent with the different light conditions during night.

An evident pattern visible in Fig. 6 is the low MVBS levels during the day and the high levels during night between 150 and $250 \mathrm{~m}$. The alternation between night and day is clearly visible in Fig. 6, as is the presence of some groups performing migrations throughout the whole investigated water column (about 100-300 m); although we did not sample them, these could be macrozooplanktonic organisms, as suggested by Pinot and Jansà (2001) and Heywood (1996).

As described earlier (see Fig. 4a), August is generally a period of low MVBS anomalies, with the exception of the most superficial bins. The increase in phytoplanktonic biomass in the layer between 60 and $80 \mathrm{~m}$, as shown in Fig. 2d, can be explained by the summer deepening of the DCM, which is possibly accompanied by a descent of the zooplankton maximum (i.e. from the very surface layer, outside the range of the ADCP, down to $60-80 \mathrm{~m}$ of depth; see Fig. 4a). This is consistent with the behaviour of the sampled community, e.g. Clausocalanus spp. and Oithona spp. (Scotto di Carlo, 1984).

\subsection{Primary and secondary production}

To understand how primary production drives the seasonal cycle of secondary production (shown in Fig. 4a) in the Corsica Channel, in Fig. 7a a comparison is made between the temporal evolution of the $8 \mathrm{~d}$ Chl $a$ average in the area of the mooring location and the $8 \mathrm{~d}$ averages of the integrated MVBS anomalies (obtained by summing up, along the vertical, the MVBS anomalies of each bin) of the whole investi- gated water column for the shallow layer (73-201 m) and the deep layer (201-378 m) during the whole deployment period.

It is clearly visible that MVBS anomalies and Chl $a$ have a similar temporal evolution, with only slight differences in the timing of seasonal peaks. In late November 2014 a small $\mathrm{Chl} a$ peak and a contemporary peak of MVBS occurred. Between early February and March 2015 an important zooplankton bloom follows a Chl $a$ peak in January 2015 and occurred while Chl $a$ again peaked in March 2015. In summer 2015 there were three little MVBS peaks that are absent in the summers of 2014 and 2016, which explains the high standard deviation of the monthly means during summer shown in Fig. 4b. Finally, in late winter $2016 \mathrm{Chl} a$ reached its annual maximum, which was accompanied by a bloom in secondary production.

To further investigate the primary and secondary production blooms, in Fig. 7b the results of a lagged correlation analysis between MVBS (total, shallow and deep) and Chl $a$ are shown. When comparing the total MVBS with $\mathrm{Chl} a$, there is a lag of about 1 week, while the deep MVBS and the $\mathrm{Chl} a$ series co-vary with the same timing (on the $8 \mathrm{~d}$ window), with no lag. On the other hand, when considering only the shallow MVBS the peaks in phytoplankton biomass precede the peaks in zooplankton biomass by about 3.5 weeks. The pattern of shallow MVBS vs. Chl $a$ is consistent with previous knowledge, according to which about a month after the surface phytoplankton bloom, a zooplanktonic bloom develops (e.g. Truscott and Brindley, 1994). The small lag we found for total MVBS vs. Chl $a$ and the zero lag for deep MVBS vs. Chl $a$ are somewhat unexpected, but it is necessary to keep in mind that the temporal resolution of the Chl $a$ field from the satellite is $8 \mathrm{~d}$ and that it is an exponentially weighted near-surface value and not an integrated value of the phytoplankton biomass within the whole eu- 

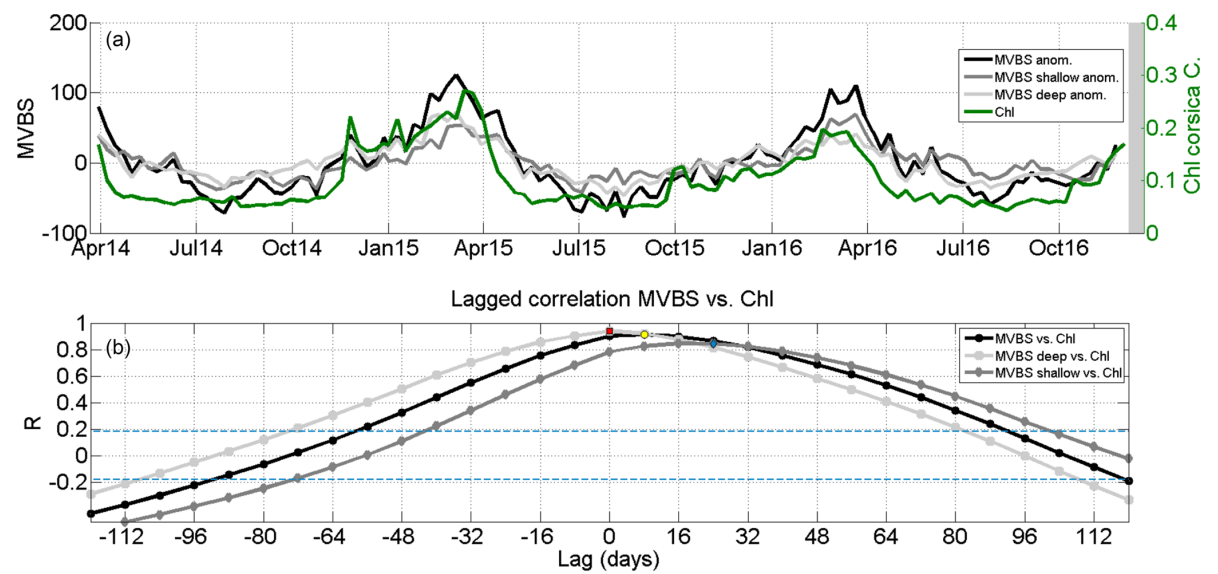

Figure 7. (a) Time series of integrated anomalies of MVBS (whole water column; dB re $(4 \pi \mathrm{m})^{-1}$ ), MVBS in the layer $73-201 \mathrm{~m}(\mathrm{MVBS}$ shallow), MVBS in the layer 201-378 m (MVBS deep) and surface chlorophyll $a$ concentration from satellite data $\left(\mathrm{Chl} a\right.$ in $\left.\mathrm{mg} \mathrm{m}^{-3}\right)$ at the mooring location in the Corsica Channel. (b) Lagged correlation analysis between MVBS (whole water column, shallow, deep) and Chl $a$. Blue lines indicate the $95 \%$ confidence bounds. The red square, the yellow circle and the blue diamond indicate the maximum significant correlation at lags of 0,8 and $24 \mathrm{~d}$, respectively, between deep MVBS and Chl $a$, total MVBS (top-bottom) and Chl $a$, and shallow MVBS and Chl $a$.

photic layer (down to the DCM). Furthermore, the MVBS data do not reach the very surface layer and the very bottom layer, where some zooplankton organisms might concentrate or peak with different timings. In addition, according to Madin et al. (2001) if the bulk of zooplankton within a water column is composed of vertical migrators, its growth dynamics are not necessarily only coupled to surface primary production.

Zooplanktonic biomass and distribution are strongly related to hydrodynamic processes (Champalbert, 1996). Due to the mainly northward current and the role of hydrodynamic processes in the Corsica Channel, we consider the study area to be strongly influenced by biological processes that occur upstream, i.e. in the northern Tyrrhenian Sea, an oligotrophic sea that comprises neritic waters in which zooplanktonic biomass might be higher and their blooms can occur earlier compared to oceanic waters. Phytoplanktonic blooms in the neritic areas of the northern Tyrrhenian Sea and the Ligurian Sea occur in late winter early spring, which corresponds to what can be seen in Fig. 7a (Marchese et al., 2015). Strong currents could be responsible for changes in the amount of zooplankton in the water column during their blooming period (when currents are stronger; see Sect. 2), and organisms could have been brought into the region by lateral advection rather than supported by local phytoplankton blooms.

\section{Conclusions}

DVM, one of the most important survival strategies adopted by zooplankton, has been investigated in the Corsica Channel, connecting the Tyrrhenian Sea and the Ligurian Sea (western Mediterranean). An analysis of acoustic backscatter (MVBS) and vertical velocity $(W)$ data, collected by a moored ADCP over more than 2.5 years, aimed to create a picture of the migratory behaviour of zooplankton at the daily and the seasonal scale in relation to the alternation of day and night, to the seasonal stratification of the water column, and to blooms of primary producers. Along with light and food availability, stratification and DCM depth are potentially relevant drivers for the seasonal differences of zooplanktonic migratory patterns.

The most significant migrations of zooplankton in the Corsica Channel occur at sunrise (downward) and at sunset (upward). DVM is clearly recognizable in the intermediate and upper layers and less in the deep one, probably because of the presence of non-migrating epi-benthic or benthopelagic organisms. The night-time zooplanktonic biomass increases in the upper layers and decreases in deep layers due to nocturnal feeding on phytoplankton or even zooplankton in the euphotic layer, as is done by strong migrators like some chaetognaths (Pearre, 2003). The net samplings evidenced copepods as the most abundant group, followed by other taxa, mainly appendicularians and chaetognaths, and by cladocerans. The zooplankton night-time descent is a well-known behavioural pattern (nocturnal sinking) when sated organisms move downward to avoid predation (Tarling et al., 2002).

At the daily scale, MVBS peaks from 2 to $4 \mathrm{~h}$ before sunset, especially during zooplanktonic blooming periods, with the alternation of upward and downward motions closely following the seasonality of sunrise and sunset times. At the seasonal scale, acoustic backscatter clearly presents periodic oscillations and is higher between late winter and early spring. This bloom in secondary production appears to be stronger 
in deep layers and during its peak it involves the whole investigated water column. The bloom is linked to the alternation of stratified and mixing conditions in the water column (MVBS increases when stratification is weaker and the thermocline is almost absent), to the DCM depth, and to the seasonality of phytoplankton blooms. The blooming period is characterized by a downward movement in the deeper layers and an upward movement in the upper layers throughout the day, while during the non-blooming period, zooplanktonic biomass maxima split along the water column, with one group of organisms located close to the DCM and the other one in the deep layer (below $300 \mathrm{~m}$ ). In the course of the day the mid-depth zooplanktonic biomass minimum becomes thicker, expanding mainly towards the deeper levels. The superficial group, close to the DCM, is especially evident during the zooplanktonic non-blooming period because of the shallower thermocline and the stronger irradiance during summer (as also found by Pinot and Jansà, 2001). During the zooplanktonic blooming period the bimodal distribution of MVBS is weaker and the MVBS minimum layer is thinner and resides at shallower depths compared to the non-blooming period. In addition, the day-to-night differences in zooplanktonic biomass of this layer are less pronounced during the blooming period. It appears that in the investigated water column upward motions are intensified during the blooming period. Consistent with the hypothesis of Hardy and Gunther (1935) and Huggett and Richardson (2000), high food availability results in intensified migration, while scarce food availability results in less intense migration, given the necessity to feed in surface layers also during the day (in spite of the predation risk) in order to compensate for food lack. It is noteworthy, however, that the observed differences between the two periods might not be only correlated with food availability, but might also be a consequence of a community shift or of other seasonally changing environmental factors, e.g. stratification, thermocline depth and position of the DCM.

A spectral analysis confirms the predominance of nocturnal DVM behaviour in this area. Still, other migration patterns (twilight and reverse) could be recognized, probably performed by a minority of organisms. Other peaks at higher frequencies are linked to different migration patterns along the migratory continuum defined by Haney (1988). Longer periods have been identified that correspond to the moon cycle, seasons, and the broader zooplanktonic blooming and non-blooming periods. Bozzano et al. (2014) found that in the shallow water column $(0-80 \mathrm{~m})$ of the Ligurian Sea the zooplanktonic biomass follows the primary production signal with a delay of about 1 month, a result that is consistent with the findings of the present study, with primary production peaks preceding the peaks in shallow secondary production by $24 \mathrm{~d}$ in the Corsica Channel. The absence of any temporal lag when comparing deep MVBS vs. Chl $a$ in the Corsica Channel is somewhat unexpected, but other studies also showed that zooplanktonic biomass peaks are often co- incident (no lag) with chlorophyll maxima (e.g. Jiang et al., 2007).

Knowledge about zooplankton migratory patterns, especially on long timescales (seasonal to interannual), is severely limited because of the difficulties related to net sampling (particularly in the open sea) and to time-consuming taxonomic determinations. Zooplankton plays a pivotal role in the marine food web, biological pump and carbon sequestration; therefore, an automatic measurement system with high temporal and spatial coverage, provided by the ADCP, greatly contributes to the understanding of zooplankton distribution along the water column in different seasons and at different hours of the day, information that is relevant for the modelling of the complex marine biogeochemical mechanisms in which zooplankton is involved. Long time series of acoustic data allows us to shed light on scales not resolved by traditional net sampling, and this application is a good example of the intense exploitation of existing datasets for multiple purposes.

Data availability. ADCP and CTD data can be provided upon request by the authors. SST field data (27 August 2015, ${ }^{\circ} \mathrm{C}$ ) can be downloaded from the Copernicus catalogue CMEMS (http://marine.copernicus.eu/services-portfolio/access-to-products/ ?option=com_csw\&view=details\&product_id=SST_MED_SST_ L3S_NRT_OBSERVATIONS_010_012, CMEMS, 2019).

Competing interests. The authors declare that they have no conflict of interest.

Special issue statement. Coastal marine infrastructure in support of monitoring, science, and policy strategies.

Acknowledgements. The authors thank the captains, crews and technicians of the Italian vessels R/V Urania and R/V Minerva Uno. Finally, we would like to thank two anonymous reviewers for the constructive criticism and valuable suggestions that greatly helped to improve the paper.

Financial support. This research has been supported by the European Commission (project FP7 OCEAN CERTAIN, grant no. 603773, and project H2020 JERICO-NEXT, grant no. 654410), the Ministero dello Sviluppo Economico (SSD Pesca project), the Ministero dell'Istruzione, dell'Università e della Ricerca (RITMARE flagship project), the Ministero dell'Ambiente e della Tutela del Territorio (implementation of the Marine Strategy Framework Directive in Italian waters), and the CIESM (Hydrochanges Programme).

Review statement. This paper was edited by Jukka Seppala and reviewed by two anonymous referees. 


\section{References}

Alcaraz, M.: Vertical distribution of zooplankton biomass during summer stratification in the Western Mediterranean, Proc. 19th Eur. Mar. Biol. Symp., 9 135-143, 1985.

Andersen, V., François, F., Sardou, J., Picheral, M., Scotto, M., and Nival, P.: Vertical distributions of macroplankton and micronekton in the Ligurian and Tyrrhenian Seas (northwestern Mediterranean), Oceanol. Acta, 21, 655-676, https://doi.org/10.1016/S0399-1784(98)90007-X, 1998.

Angel, M. V.: The thermocline as an ecological boundary, Sarsia, 34, 229-312, 1968.

Aracri, S., Borghini, M., Canesso, D., Chiggiato, J., Durante, S., Schroeder, K., Sparnocchia, S., Vetrano, A., Honda, T., Kitawaza, Y., Kawahara, H., and Nakamura, T.: Trials of an autonomous profiling buoy system, J. Oper. Oceanogr., 9, 176-184, https://doi.org/10.1080/1755876X.2015.1115631, 2016.

Astraldi, M. and Gasparini, G. P.: The seasonal characteristics of the circulation in the north Mediterranean basin and their relationship with the atmospheric- climatic conditions, J. Geophys. Res., 97, 9531-9540, https://doi.org/10.1029/92JC00114, 1992.

Bakun, A. and Agostini, V. N.: Seasonal patterns of wind-induced upwelling/downwelling in the Mediterranean Sea, Sci. Mar., 65, 243-257, 2001.

Bozzano, R., Fanelli, E., Pensieri, S., Picco, P., and Schiano, M. E.: Temporal variations of zooplankton biomass in the Ligurian Sea inferred from long time series of ADCP data, Ocean Sci., 10, 93-105, https://doi.org/10.5194/os-10-93-2014, 2014.

Brierley, A. S., Brandon, M. A., and Watkins, J. L.: An assessment of the utility of an acoustic Doppler current profiler for biomass estimation, Deep-Sea Res. Pt. I, 45, 1555-1573, 1998.

Champalbert, G.: Characteristics of zooplankton standing stock and communities in the Western Mediterranean Sea: Relations to hydrology, Sci. Mar., 60, 97-113, 1996.

Chu, D., Stanton, T. K., and Wiebe, P. H.: Frequency dependence of sound backscattering from live individual zooplankton, ICES J. Mar. Sci., 49, 97-106, https://doi.org/10.1093/icesjms/49.1.97, 1992.

Clarke, G.: Factors affecting the vertical distribution of copepods, Ecol. Monogr., 4, 530-540, https://doi.org/10.2307/1961656, 1934.

CMEMS: Mediterranean Sea - High Resolution and Ultra High Resolution L3S Sea Surface Temperature, available at: http://marine.copernicus.eu/services-portfolio/ access-to-products/?option=com_csw\&view=details\&product id=SST_MED_SST_L3S_NRT_OBSERVATIONS_010_012, last access: 20 May 2019.

D'Ortenzio, F. and Ribera d'Alcalà, M.: On the trophic regimes of the Mediterranean Sea: a satellite analysis, Biogeosciences, 6, 139-148, https://doi.org/10.5194/bg-6-139-2009, 2009.

Deines, K. L.: Backscatter estimation using Broadband acoustic Doppler current profilers, in Proceedings of the IEEE Sixth Working Conference on Current Measurement, San Diego, CA, USA, 249-253, 1999.

Estrada, M.: Deep phytoplankton and chlorophyll maxima in the Western Mediterranean, In: Mediterranean Marine Ecosystems, edited by: Moraitou-Apostolopoulou, M. and Kiortsis, V., Springer, Boston, MA, 247-277, https://doi.org/10.1007/978-14899-2248-9_12, 1985.
Eyden, D.: Specific gravity as a factor in the vertical distribution of plankton, Biol. Rev. Camb. Philos. Soc., 1, 49-55, https://doi.org/10.1111/j.1469-185X.1923.tb00531.x, 1923.

Fisher, F. H. and Simmons, V. P.: Sound absorption in sea water, J. Acoust. Soc. Am., 62, 558-564, https://doi.org/10.1121/1.381574, 1977.

Flagg, C. N. and Smith, S. L.: On the use of the acoustic Doppler current profiler to measure zooplankton abundance, Deep-Sea Res., 36, 455-474, https://doi.org/10.1016/01980149(89)90047-2, 1989.

Gibbons, M. J.: Vertical migration and feeding of Euphausia lucens at two $72 \mathrm{~h}$ stations in the southern Benguela upwelling region, Mar. Biol. Int. J. Life Ocean. Coast. Waters, 116, 257258, https://doi.org/10.1007/BF00350016, 1993.

Häfker, N. S., Meyer, B., Last, K. S., Pond, D. W., Hüppe, L., and Teschke, M.: Circadian Clock Involvement in Zooplankton Diel Vertical Migration, Curr. Biol., 27, 2194-2201, https://doi.org/10.1016/j.cub.2017.06.025, 2017.

Haney, J. F.: Diel patterns of zooplankton behavior, Bull. Mar. Sci., 43, 583-603, 1988.

Hardy, A. C.: Some problems of pelagic life, in: Essays in marine biology being the Richard Elmhirst Memorial Lectures, edited by: Marshall, S. M., and Orr, A. P., Oliver and Boyd, Edinburgh, UK, 101-121, 1953.

Hardy, A. C. and Gunther, E. R.: The plankton of the South Georgia whaling grounds and adjacent waters, 1926-1927, Discovery Rept., 11, 1-456, 1935.

Hays, G. C.: A review of the adaptive significance and ecosystem consequences of zooplankton diel vertical migrations, Hydrobiologia, 503, 163-170, https://doi.org/10.1023/B:HYDR.0000008476.23617.b0, 2003.

Hays, G. C., Harris, R. P., and Head, R. N.: The vertical nitrogen flux caused by zooplankton diel vertical migration, Mar. Ecol. Prog. Ser., 160, 57-62, https://doi.org/10.3354/meps160057, 1997.

Heywood, K. J.: Diel vertical migration of zooplankton in the northeast Atlantic, J. Plankton Res., 18, 163-184, https://doi.org/10.1093/plankt/18.2.163, 1996.

Huggett, J. A. and Richardson, A. J.: A review of the biology and ecology of Calanus agulhensis off South Africa, ICES J. Mar. Sci., 57, 1834-1849, https://doi.org/10.1006/jmsc.2000.0977, 2000.

Iida, K., Mukai, T., and Hwang, D. J.: Relationship between acoustic backscattering strength and density of zooplankton in the sound-scattering layer, ICES J. Mar. Sci., 53, 507-512, https://doi.org/10.1006/jmsc.1996.0073, 1996.

IOC, SCOR and IAPSO: The international thermodynamic equation of seawater - 2010: Calculation and use of thermodynamic properties, Intergovernmental Oceanographic Commission, Manuals and Guides No. 56, UNESCO (English), available at: http: //unesdoc.unesco.org/images/0018/001881/188170e.pdf (last access: 20 May 2019), 196 pp., 2010.

Jiang, S., Dickey, T. D., Steinberg, D. K., and Madin, L. P.: Temporal variability of zooplankton biomass from ADCP backscatter time series data at the Bermuda Testbed Mooring site, Deep-Sea Res. Pt. I, 54, 608-636, https://doi.org/10.1016/j.dsr.2006.12.011, 2007.

Longhurst, A. R. and Glen Harrison, W.: The biological pump: Profiles of plankton production and consumption in the upper ocean, 
Prog. Oceanogr., 22, 47-123, https://doi.org/10.1016/00796611(89)90010-4, 1989.

Madin, L. P., Horgan, E. F., and Steinberg, D. K.: Zooplankton at the Bermuda Atlantic Time-series Study (BATS) station: Diel, seasonal and interannual variation in biomass, 1994-1998, DeepSea Res. Pt. II, 48, 2063-2082, https://doi.org/10.1016/S09670645(00)00171-5, 2001.

Marchese, C., Lazzara, L., Pieri, M., Massi, L., Nuccio, C., Santini, C. and Maselli, F.: Analysis of Chlorophyll $a$ and Primary Production Dynamics in North Tyrrhenian and Ligurian Coastal-Neritic and Oceanic Waters, J. Coast. Res., 31, 690-701, https://doi.org/10.2112/JCOASTRES-D-13-00210.1, 2015.

Mauchline, J.: The Biology of Calanoid Copepods, Adv. Mar. Biol., 33, 1-710, 1998.

McGehee, D. E., Demer, D. A., and Warren, J. D.: Zooplankton in the Ligurian Sea: Part I. Characterization of their dispersion, relative abundance and environment during summer 1999, J. Plankton Res., 26, 1409-1418, https://doi.org/10.1093/plankt/fbh132, 2004.

Millot, C. and Taupier-Letage, I: Circulation in the Mediterranean Sea, in: The Mediterranean Sea. Handbook of Environmental Chemistry, edited by: Saliot A., Springer, Berlin, Heidelberg Germany, 29-66, https://doi.org/10.1007/b107143, 2005.

Moriarty, R., Buitenhuis, E. T., Le Quéré, C., and Gosselin, M.P.: Distribution of known macrozooplankton abundance and biomass in the global ocean, Earth Syst. Sci. Data, 5, 241-257, https://doi.org/10.5194/essd-5-241-2013, 2013.

Neverman, D. and Wurtsbaugh, W. A.: The thermoregulatory function of diel vertical migration for a juvenile fish, Cottus extensus, Oecologia, 98, 247-256, https://doi.org/10.1007/BF00324211, 1994.

Pearre, S.: Eat and run? The hunger/satiation hypothesis in vertical migration: History, evidence and consequences, Biol. Rev. Camb. Philos. Soc., 78, 1-79, https://doi.org/10.1017/S146479310200595X, 2003.

Pinca, S. and Dallot, S.: Meso- and macrozooplankton composition patterns related to hydrodynamic structures in the Ligurian Sea (Trophos-2 experiment, April-June 1986), Mar. Ecol. Prog. Ser., 126, 49-65, https://doi.org/10.3354/meps126049, 1995.

Pinot, J. M. and Jansá, J.: Time variability of acoustic backscatter from zooplankton in the Ibiza Channel (western Mediterranean), Deep-Sea Res. Pt. I, 48, 1651-1670, https://doi.org/10.1016/S0967-0637(00)00095-9, 2001.

Potiris, E., Frangoulis, C., Kalampokis, A., Ntoumas, M., Pettas, M., Petihakis, G., and Zervakis, V.: Acoustic Doppler current profiler observations of migration patternsof zooplankton in the Cretan Sea, Ocean Sci., 14, 783-800, https://doi.org/10.5194/os14-783-2018, 2018.

Richards, S. A., Possingham, H. P., and Noye, J.: Diel vertical migration: Modelling light-mediated mechanisms, J. Plankton Res., 18, 2299-2222, https://doi.org/10.1093/plankt/18.12.2199, 1996.

Ringelberg, J.: Diel Vertical Migration of Zooplankton in Lakes and Oceans: causal explanations and adaptative significances, Springer Science, Business Media B.V., 1-356, https://doi.org/10.1007/978-90-481-3093-1, 2010.

Sardou, J., Etienne, M., and Andersen, V.: Seasonal abundance and vertical distributions of macroplankton and micronekton in the
Northwestern Mediterranean Sea, Oceanol. Acta, 19, 645-656, 1996.

Schnetzer, A. and Steinberg, D. K.: Active transport of particulate organic carbon and nitrogen by vertically migrating zooplankton in the Sargasso Sea, Mar. Ecol. Prog. Ser., 234, 71-84, https://doi.org/10.3354/meps234071, 2002.

Schroeder, K., Millot, C., Bengara, L., Ben Ismail, S., Bensi, M., Borghini, M., Budillon, G., Cardin, V., Coppola, L., Curtil, C., Drago, A., El Moumni, B., Font, J., Fuda, J. L., García-Lafuente, J., Gasparini, G. P., Kontoyiannis, H., Lefevre, D., Puig, P., Raimbault, P., Rougier, G., Salat, J., Sammari, C., Sánchez Garrido, J. C., Sanchez-Roman, A., Sparnocchia, S., Tamburini, C., Taupier-Letage, I., Theocharis, A., Vargas-Yáñez, M., and Vetrano, A.: Long-term monitoring programme of the hydrological variability in the Mediterranean Sea: a first overview of the HYDROCHANGES network, Ocean Sci., 9, 301-324, https://doi.org/10.5194/os-9-301-2013, 2013.

Scotto di Carlo, B., Ianora, A., Fresi, E., and Hure, J.: Vertical zonation patterns for Mediterranean copepods from the surface to $3000 \mathrm{~m}$ at a fixed station in the Tyrrhenian Sea, J. Plankton Res., 6, 1031-1056, 1984.

Siokou-Frangou, I., Christaki, U., Mazzocchi, M. G., Montresor, M., Ribera d'Alcalé, M., Vaqué, D., and Zingone, A.: Plankton in the open Mediterranean Sea: a review, Biogeosciences, 7, 15431586, https://doi.org/10.5194/bg-7-1543-2010, 2010.

Stuart, V. and Verheye, H. M.: Diel migration and feeding patterns of the chaetognath, Sagitta jriderici, off the west coast of South Africa, J. Mar. Res., 49, 493-515, https://doi.org/10.1357/002224091784995819, 1991.

Tarling, G. A., Matthews, J. B. L., David, P., Guerin, O., and Buchholz, F.: The swarm dynamics of northern krill (Meganyctiphanes norvegica) and pteropods (Cavolinia inflexa) during vertical migration in the Ligurian Sea observed by an acoustic Doppler current profiler, Deep-Sea Res. Pt. I, 48, 1671-1686, https://doi.org/10.1016/S0967-0637(00)00105-9, 2001.

Tarling, G. A., Jarvis, T., Emsley, S. M., Matthews, J. B. L.: Midnight sinking behaviour in Calanus finmarchicus: a response to satiation or krill predation?, Mar. Ecol. Prog. Ser., 240, 183-194, 2002.

Teledyne RD Instruments: Acoustic Doppler Current Profiler principles of operation a practical primer, P/N 951-6069-00, 2011.

Thomson, R. E. and Emery, W. J.: Data Analysis Methods in Physical Oceanography, Elsevier Science, 1-728, 2014.

Truscott, J. E. and Brindley, J.: Ocean plankton populations as excitable media, Bull. Math. Biol., 56, 981-988, https://doi.org/10.1007/BF02458277, 1994.

Ursella, L., Cardin, V., Batistić, M., Garić, R., and Gačić, M.: Evidence of zooplankton vertical migration from continuous Southern Adriatic buoy current-meter records, Prog. Oceanogr., 167, 78-96, https://doi.org/10.1016/j.pocean.2018.07.004, 2018.

Valle-Levinson, A., Castro, L., Cáceres, M., and Pizarro, O.: Twilight vertical migrations of zooplankton in a Chilean fjord, Prog. Oceanogr., 129, 114-124, https://doi.org/10.1016/j.pocean.2014.03.008, 2014.

van Haren, H.: Monthly periodicity in acoustic reflections and vertical motions in the deep ocean, Geophys. Res. Lett., 34, L12603, https://doi.org/10.1029/2007GL029947, 2007. 
van Haren, H.: Internal wave - zooplankton interactions in the Alboran Sea (W-Mediterranean), J. Plankton Res., 36, 1124-1134, https://doi.org/10.1093/plankt/fbu031, 2014.

van Haren, H. and Compton, T. J.: Diel Vertical Migration in Deep Sea Plankton Is Finely Tuned to Latitudinal and Seasonal Day Length, PLOS ONE, 8, e64435, https://doi.org/10.1371/journal.pone.0064435, 2013.

Vinogradov, M. E.: Some Problems of Vertical Distribution of Meso- and Macroplankton in the Ocean, Adv. Mar. Biol., 32, 197, https://doi.org/10.1016/S0065-2881(08)60015-2, 1997.

Volpe, G., Santoleri, R., Vellucci, V., Ribera d'Alcalà, M., Marullo, S. and D'Ortenzio, F.: The colour of the Mediterranean Sea: Global versus regional bio-optical algorithms evaluation and implication for satellite chlorophyll estimates, Remote Sens. Environ., 107, 625-638, https://doi.org/10.1016/j.rse.2006.10.017, 2007.
Warren, J. D., Demer, D. A., Mcgehee, D. E., Mento, R. D. I., and Fabrizio Borsani, J.: Zooplankton in the Ligurian Sea: Part II, Exploration of their physical and biological forcing functions during summer 2000, J. Plankton Res., 26, 1419-1427, https://doi.org/10.1093/plankt/fbh129, 2004.

Wormuth, J. H., Ressler, P. H., Cady, R. B., and Harris, E. J.: Zooplankton and Micronekton in Cyclones and Anticyclones in the Northeast Gulf of Mexico, Gulf of Mexico Science, 18, 23-34, 2000.

Zaret, T. M. and Suffern, J. S.: Vertical migration in zooplankton as a predator avoidance mechanism, Limnol. Oceanogr., 21, 804813, https://doi.org/10.4319/lo.1976.21.6.0804, 1976. 